\title{
,anu \\ Multi-Criteria Decision Support System for Smart and Sustainable Machining Process
}

\author{
Luka Celent $^{1}$, Marko Mladineo ${ }^{2, *(\mathbb{D}}$, Nikola Gjeldum ${ }^{2}$ and Marina Crnjac Zizic ${ }^{2}$ \\ 1 School of Mechanical and Design Engineering, University of Portsmouth, Portsmouth PO1 3DJ, UK; \\ luka.celent@port.ac.uk \\ 2 Faculty of Electrical Engineering, Mechanical Engineering and Naval Architecture, University of Split, \\ Rudera Boskovica 32, 21000 Split, Croatia; ngjeldum@fesb.hr (N.G.); mcrnjac@fesb.hr (M.C.Z.) \\ * Correspondence: mmladine@fesb.hr; Tel.: +385-21-305-939
}

Citation: Celent, L.; Mladineo, M.; Gjeldum, N.; Crnjac Zizic, M. Multi-Criteria Decision Support System for Smart and Sustainable Machining Process. Energies 2022, 15, 772. https://doi.org/10.3390/ en15030772

Academic Editors: Andrew Kusiak and Surender Reddy Salkuti

Received: 22 December 2021

Accepted: 19 January 2022

Published: 21 January 2022

Publisher's Note: MDPI stays neutral with regard to jurisdictional claims in published maps and institutional affiliations.

Copyright: (c) 2022 by the authors. Licensee MDPI, Basel, Switzerland This article is an open access article distributed under the terms and conditions of the Creative Commons Attribution (CC BY) license (https:// creativecommons.org/licenses/by/ $4.0 /)$.

\begin{abstract}
Sustainatableble development assumes the meeting of humanity's everyday needs and development goals while sustaining the ability of nature to provide the resources and ecosystem on which the economy and society depend. It means that an increase of economic benefit cannot be a single optimization problem anymore, instead, the multi-criteria approach is used with the accent on ecology and social welfare. However, it is not easy to harmonize these aims with machining, which is a well known industrial pollutant. On the other hand, new industrial paradigms such as Industry 4.0/5.0, are driving toward the smart concept that collects data from the manufacturing process and optimizes it in accordance with productivity and/or ecologic aims. In this research, the smart concept is used through the development of the multi-criteria decision support system for the selection of the optimal machining process in terms of sustainability. In the case of milling process selection, it has been demonstrated that green machining, without a multi-criteria approach, will always remain an interesting research option, but not a replacement for conventional machining. However, when applying realistic ecological and social criteria, green machining becomes a first choice imperative. The multi-criteria decision-making PROMETHEE method is used for the comparison and ranking, and validation of results is made through criteria weights sensitivity analysis. The contribution of this concept is that it could also be applied to other manufacturing processes.
\end{abstract}

Keywords: smart manufacturing; sustainable machining; decision support system; PROMETHEE method; Industry 4.0

\section{Introduction}

Machining is still a leading manufacturing process with a share of $60-80 \%$ in manufacturing industries of developed countries, and it has a share of $15 \%$ of total product costs [1]. For decades, optimization aims in manufacturing were: manufacture more, manufacture faster, and manufacture with fewer costs. However, the idea of sustainable development [2] does not see an economic benefit as the only optimization criterion. Instead, two more criteria are added-ecology and social welfare-making sustainability an intersection of economy, ecology, and social welfare. World leaders [3] and moral authorities [4] agreed that care for "our common home" is imperative, which requires immediate actions. According to this, the development of sustainable manufacturing processes, so called green machining, is becoming unavoidable for the manufacturing industry [5].

In the context of sustainability, machining processes are problematic. By generating different offensive pollutants and by-products, machining has a negative effect on ecology and health of workers. In the $1980 \mathrm{~s}$ and $1990 \mathrm{~s}$, there were trends toward the clean production and green machining [6]. However, the economic side of green machining was problematic, because it represented a higher cost of manufacturing, therefore, some of the authors were not considering its sustainability, but just its preservation of the 
environment [6]. If looking from the environmental point of view, the usage of cutting fluids in machining is its major ecologic problem, however, it also increases productivity. The main purpose of cutting fluid application is to reduce heat generation at the cutting zone in order to prevent overheating of the cutting tool that could cause tool breakage and improve the surface roughness. Tool wear and surface roughness are always used as a quality indicator of a product. Thus, within machining processes, cutting fluids are used in order to increase productivity. The historical development of cutting fluids is brought forth by Byers [7], who concludes that it was not until the early $1960 \mathrm{~s}$ that scientists began to recognize and express concerns about the harmful effects of cutting fluids on the humans and environment.

At the beginning of the 21st century, on the global level, manufacturers were using close to 1.4 billion liters of cutting fluids, forming a significant demand for this nonrenewable type of raw material [8]. The consumption of cutting fluids in the machining industry alone for the European Union (EU) stands at approximately 300 million liters per year [9]. Approximately $85 \%$ of cutting fluids used around the world are mineralbased cutting fluids, which cause significant environmental pollution throughout their lifecycle [10]. Having a limited lifespan, cutting fluids must be properly disposed of after use. Satisfactory disposal considers recycling or burning as a fuel. In the EU, only $32 \%$ of the total amount of annually used cutting fluids is disposed of in an environmentally friendly way [11]. Considering the losses of cutting fluids through evaporation, uncontrolled leakage, residual quantities on the workpiece, cutting tool, or swarf, it can be established that in these ways, almost $30 \%$ of the annual amount of cutting fluids used is taken out of the production system [12]. Cutting fluids are hazardous both on storage and disposal, requiring special treatment in order to remove the toxic components inside the cutting fluids before disposal. Disposal of cutting fluids raises a number of environmental issues, especially considering that it is one of the most complex types of industrial waste [13] Cutting fluids are complex in their composition, and as such, they pose a significant health hazard throughout their life cycle. The American National Institute for Occupational Safety and Health estimates that annually, 1.2 million workers are exposed to the possible harmful effects of cutting fluids [14]. Among the most common diseases caused by exposure to cutting fluids, Ueno et al. [15] highlighted various skin diseases, while Mackerer [16] pointed out malignant and non-malignant diseases of the respiratory system. Other health hazards, including oil mist and oil vapor effects, bactericide effects, genotoxicity, the presence of cancerogenic substances and heavy metal particles [17], represent the use of cutting fluids as a burning issue with possible numerous short-term and long-term consequences for humans [18]. Regarding the economic aspects of using cutting fluids, Davim [19] wrote about its consumption in thousands of tons, allocation in billions of dollars, testifying to the scale of use and costs of cutting fluids. The costs associated with the use of cutting fluids can be up to $17 \%$ of the total production cost [20]. In the case of machining of hard-to-cut materials, that percentage can grow up to $30 \%$ of total production costs [21]. When taking into consideration the previously mentioned disposal of cutting fluids, the cost of disposal can be up to two to four times the cutting fluid purchasing costs [22].

Current usage of cutting-fluids in the machining process, which results in up to $30 \%$ of uncontrolled loss of the cutting fluids [12], makes machining a barrier in the path toward a circular economy. That fact represents an enormous issue, especially in the European Union, since the EU set a $\mathrm{CO}_{2}$ reduction and circular economy as the main ecology aims for the next decades. The concept of Industry 5.0, presented by the European Commission [23,24] as an update of Industry 4.0 [25], also sees circular economy [26] as one of its key goals (Figure 1). The main contribution of Industry 4.0/5.0 in achieving these goals is in economic savings through better energy and resource management provided by big data analytics and optimization based on digital twins [27]. Nevertheless, the concept of Industry 4.0/5.0 is pervasive, affecting the product, process, and the whole production system [27]. 


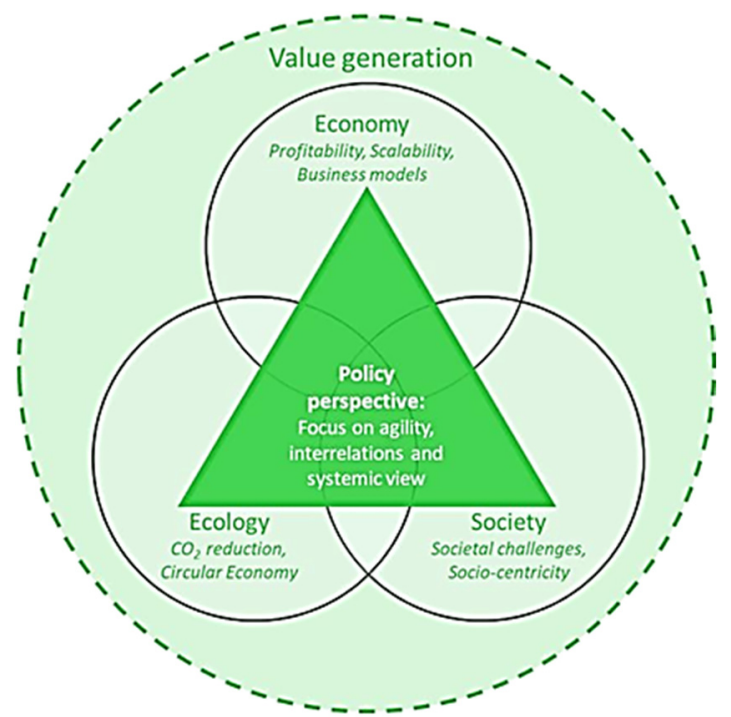

Figure 1. The main goals associated with the concept of Industry 5.0 [24].

Therefore, there is an imperative to analyze the usage of cutting-fluids in machining from the aspect of the circular economy, including social aspects. This represents a great challenge for scientists in the search for better solutions for cooling and lubrication in the machining process. These new solutions must be technically and economically viable, but also they must not represent a threat to humans or the environment. At the moment, there are several green machining techniques that add a dose of sustainability into the machining process.

\subsection{Green Machining Techniques}

Enactment of new legislation that will protect and enhance both human health and the environment, together with an increase in the cost of use and disposal of the cutting fluids, have led to extensive scientific research towards so-called environmentally friendly and potentially sustainable green machining [28]. In this light, the machining industry is focused on trying to achieve dry machining, as well as new alternative methods and systems such as minimum quantity lubrication (MQL) systems, compressed cold air cooling (CCA) systems, and cryogenic machining systems.

The advantages of a complete switch from the conventional use of cutting fluids to dry machining are multiple [29,30]: no negative impact on humans and the environment, reduction of variable machining costs, easier swarf recycling, no need for degreasing of the workpiece after the machining process, and in some cases longer tool life when high-speed machining some specific materials. In addition to cost-effectiveness and other mentioned practicalities of dry machining, Dinnie [31] also noted the increase in the company's positive image, which is one of the main ways to gain a lasting competitive advantage in the global market of today.

The intermediate solution towards reaching dry machining is the MQL method. The MQL method is the most used alternative to the conventional use of cutting fluids, and it can be classified as a semi-dry machining method. Reduction in power consumption and cutting fluid amounts can be made using this technique [32]. In the case of MQL, oil provides lubrication, while the effect of cooling and blowing off the swarf from the cutting zone is obtained by the constant presence of an airflow [33].

Both machining with the conventional use of cutting fluid and machining under MQL pose the problem of disposal of cutting fluids. A by-product of MQL is mist, which in the industrial environment can cause serious respiratory effects on the workers that are exposed to such substances [34]. CCA cooling and cryogenic machining systems have no such effect on workers and, as such, represent a strong alternative to any liquid coolant in machining. Initial studies used room-temperature compressed air, which proved ineffective 
compared to liquid coolant used during the machining process. New studies that were conducted in the conditions of the compressed cold air cooling yield the results comparable and, in some cases, even better than the use of cutting fluids. One way to perform CCA cooling is the use of specially designed systems for the preparation and distribution of compressed cold air, which requires an additional source of power $[35,36]$. Another way of performing CCA cooling is the use of a vortex tube which requires only the supply of a certain amount of air under pressure, enabling cold air-cooling conditions without the need for an additional source of power [37,38]. The phenomenon of the creation of cold air inside the vortex tube has not been fully explained yet, and different interpretations of this phenomenon can be found [39]. There are few studies focused on the effect of CCA cooling while machining, especially for milling operations. However, existing studies indicate great potential in the end milling of ASSAB 718HH mold steel with a hardness of $35 \mathrm{HRc}$ [40], hard milling of AISI D2 cold work tool steel with a hardness of $62 \mathrm{HRc}$ [31], and milling of AISI 1050 steel with a hardness of $10 \mathrm{HRc}$ [41].

Cryogenic machining involves cooling with cryogenic fluids-most often liquid nitrogen - at temperatures down to $-196^{\circ} \mathrm{C}$ [42]. Liquid helium and carbon dioxide are also used as cryogenic fluids. Similar to CCA, cryogenic fluid is applied directly to the cutting zone in order to cool down both cutting tools and workpiece. In the case of liquid nitrogen, which accounts for $78 \%$ of the earth's atmosphere and is inert, lighter than air gas, evaporation does not pose any threat in terms of environmental pollution or any danger to workers' health [43]; the same cannot be said for carbon dioxide which pollutes the atmosphere. Some researchers are proposing a system that will use already existing carbon dioxide exhaust gases within the production plant as cryogenic fluids [44]. In that case, cryogenic machining would not contribute to additional air pollution. Furthermore, the high consumption of cryogenic fluids, as well as the cost of investment in the previously mentioned systems for supplying and applying cryogenic fluids while machining, as well as the cost of cryogenic fluids itself, ultimately increases the cost of the machining process and raises the question of the economic viability of the whole cryogenic process. It can be concluded that cryogenic processes are profitable only in specific cutting conditions using high values for cutting parameters such as cutting speed and feed [45].

In the end, it is important to mention the application of cutting fluids with the usage of biodegradable cutting fluids $[32,46]$. It represents an interesting and important research topic. However, it will not be considered in this research because a cutting fluid can be biodegradable, but after machining, it still needs to be processed before the process of disposal. Namely, the cutting fluid is mixed with metal chips and particles during the machining process, so it is not biodegradable in that form, but it needs to be processed lately.

In this research, three different sets of milling experiments have been used [47]: conventional milling with the application of cutting fluids (CF), dry milling (DM), and milling with the application of compressed cold air cooling (CCA). These experiments are used as input data for the developed multi-criteria decision support system, i.e., these experiments are used for the proof of concept of the developed system.

\subsection{Decision Support System for Smart Manufacturing}

The multi-criteria perspective of sustainable development represents a significant paradigm change not just from the industrial perspective, but from the scientific perspective as well. This means a move from single-objective optimization toward multi-objective optimization and multi-criteria decision-making. Since multi-objective optimization is used for quantitative objectives, multi-criteria decision-making, which also supports qualitative criteria, can find a wider application $[48,49]$. Therefore, it was suitable to apply some multi-criteria decision-making methods in this research.

The concept of a smart system implies a function of real-time sensing of the process or environment and the possibility to actuate, i.e., to control the process. However, a smart system is not necessarily autonomous-rather, it is controlled by humans most of the time, which means that the process is subordinated to human decision-making. The 
same principle applies to the smart manufacturing concept: sensors that are part of the industrial Internet-of-Things provide "live" data and the ability to create a digital twin of the manufacturing system. The digital twin is used for optimization and simulation of the manufacturing system in order to apply changes that will optimize the production process. However, the smart manufacturing system is not a cognitive system, therefore, decisions are made by human decision-makers.

For more than 40 years, there has been an idea of enhancing human decision-making abilities by providing them artificial decision support in the form of a computer system: the decision support system (DSS). One of the DSS pioneers-Ralph H. Sprague Jr.-developed the conceptual foundation for decision support systems in 1979. He defined the main elements of the DSS [50]: data, model, and user interface (dialogue) for interaction with humans (Figure 2).

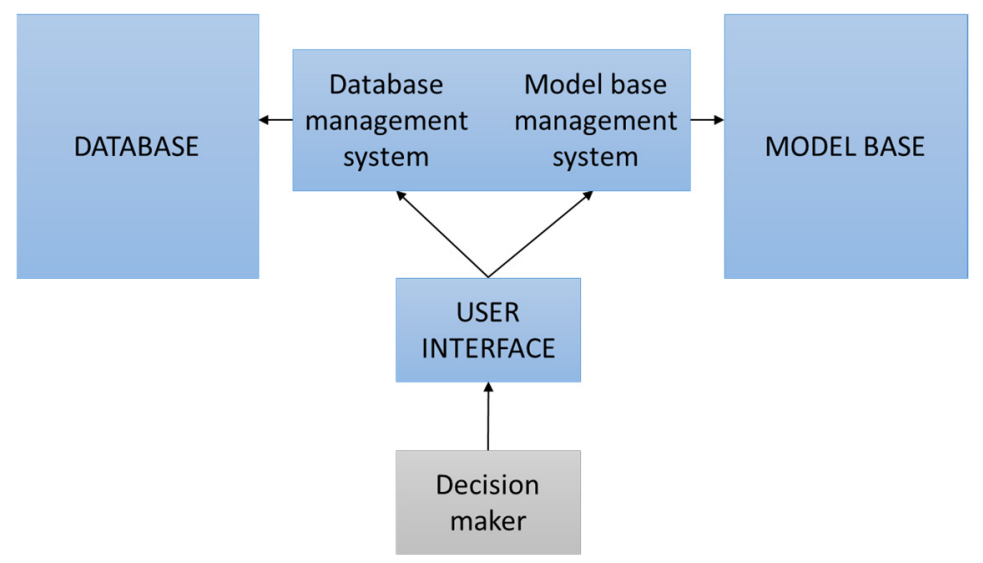

Figure 2. The main elements of the decision support system: data, model, and user interface (adapted from [50]).

In this research, the same concept of DSS (Figure 2) was used to create a multi-criteriabased decision support system for sustainable decisions in machining. The developed DSS is based on a multi-criteria decision-making PROMETHEE (Preference Ranking Organization METHod for Enrichment of Evaluations) method. As mentioned, three different sets of milling experiments - conventional milling with the application of cutting fluids (CF), dry milling (DM), and milling with the application of compressed cold air cooling (CCA) -were used to create three case studies for presentation and validation of the concept. The main research objective was to design a DSS that will ensure a proper comparison of green and conventional machining techniques, which proves that green techniques are optimal in terms of sustainability. It is a known fact that conventional machining techniques are more productive and economical than green techniques, and perhaps it will always remain that way. But, if profit is not the only optimization criterion, then green machining techniques become important. Highlighting this fact was also one of the research objectives.

Regarding existing DSS concepts for machining, most of the time, they are used to support the selection of the machining process or machine tool, but there are some authors who have focused on the selection of parameters of the machining process. Temuçin et al. [51] are using fuzzy based DSS to select machining processes aimed at non-traditional technologies. Taha and Rostam [52] are using a combination of AHP and PROMETHEE methods for the selection of machine tools, and Alberti et al. [53] are using the same problem, but they are more focused on machine characteristics and performance tests. Balazinski et al. [54] demonstrated a DSS for the selection of cutting parameters back in 1994, and it was one of the first applications of DSS in machining. Niamat et al. [55], similar to Ming et al. [56], are using multi-objective optimization to optimize electro-discharge machining process parameters. Wittbrodt and Paszek [57] developed a DSS for monitoring and forecasting tool wear based on fuzzy logic. Vidal et al. [58] are using DSS to plan milling operations by optimizing the selection of parameters. 
However, there are some research regarding DSS in machining that is closer to research presented in this paper. Plaza et al. [59] aimed to stabilize cutting forces in order to achieve higher quality, but this led to a reduction of machining efficiency. Similarly, but with differences, a kind of balanced approach is presented in this paper: balancing economic benefits and machining efficiency on one side, and preserving the natural environment and human health on the other side. Shin et al. [60] and Khan et al. [5,61] have, similarly, taken sustainability criteria into account in their research. In order to do so, they are examining and optimizing the usage of energy resources during the machining process.

To conclude, the research presented in this paper contributes to the area of application of DSS in machining with the novel approach of implementing sustainability criteria into the milling process selection, which results in sustainable and green machining. It demonstrates, on real milling experiments, how to properly balance between machining efficiency and preservation of the planet for future generations. Practical contribution of the research is that developed concept could be applied to other manufacturing processes and to other human economic activities, as well.

The rest of the paper is organized as follows: in the section "Methods", the description of proposed DSS is given together with an explanation of the PROMETHEE method. The experimental data sets for three different milling techniques that will be used as a case study are also presented. The section "Results" is divided into four subsections. The first is Case 1, in which the comparison of milling techniques is based on four quantitative criteria for economic and productivity. The next subsection is Case 2, in which the comparison of milling techniques has been extended with three additional qualitative criteria for productivity. The subsection Case 3 describes the further extension of comparison of milling techniques with 2 additional qualitative criteria for ecology and society, thus rounding up the sustainability criteria. The final subsection tests the validity of the proposed approach through criteria weights stability analysis. Finally, the conclusions and suggestions for further research are given in the "Conclusions" section.

\section{Methods}

The starting point of this research is the definition of the machining process by defining the most important inputs and outputs. A common model for the machining process is presented in Figure 3. The inputs are the type of machining (milling, turning, etc.) and its parameters (cutting speed, feed, etc.), with the definition of the machining technique (application of cutting fluids, dry machining, etc.). The outputs can be divided into value added or productivity (surface roughness, material removal rate, etc.) and non-value added or cost (tool wear, machining cost, etc.). The optimization aim of this common machining process would be to increase productivity and decrease costs.

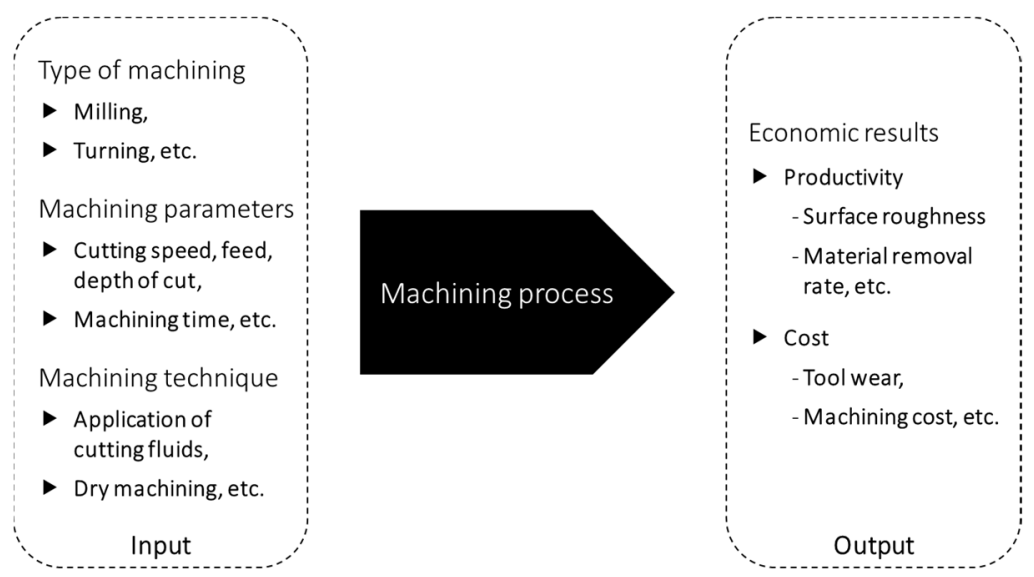

Figure 3. A common model of machining process with inputs and outputs. 
It is the common approach that, however, has a limited view on negative outputs of machining, since it is only focused on economic cost. But, what about ecological costs through the negative impact on environment and social cost through negative impact on worker's health?

In this research, a model of the machining process was extended from direct outputs of machining - technical productivity and economic cost - to indirect outputs of machiningecologic impact and threat to human health (Figure 4). Technical productivity is actually a productivity but without an economic aspect (tool wear, machining cost, etc.). Ecological impact assumes a negative impact on ecology (environment).

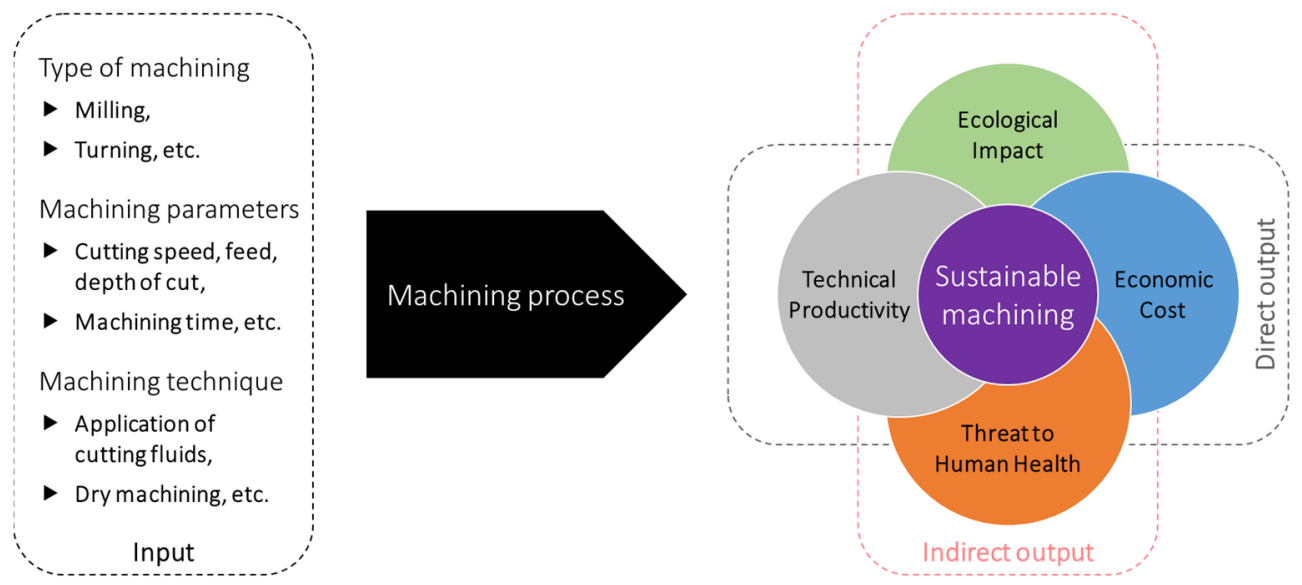

Figure 4. Proposed model of machining process with extended outputs definition.

When taking into account all proposed outputs (criteria), a machining process can be optimized in order to achieve sustainable machining. The aim of this research was to develop a decision support system for sustainable machining. The classic DSS concept was used consisting of the data, model, and user interface. An optimization model is based on multi-criteria decision-making method and uses criteria (outputs) defined in Figure 4 . The data were collected through experiments and research, and the data collection process could be automated by using smart technology in the future. The user interface was a software, in this case, Visual PROMETHEE software (Ver. 1.4, Mareschal, Bruxelles, Belgium), since it has been decided to use PROMETHEE as a multi-criteria decision-making method. The described concept of the DSS is presented in Figure 5.

Today, there are many multi-criteria decision-making methods in everyday engineering practice [62]. However, some of them are better accepted and spread because of their capability to adjust to a variety of problems: AHP [63,64], ELECTRE [64], TOPSIS [64,65], and PROMETHEE [66]. A crucial issue is to decide which method is the most adequate for a particular problem, but most of the time, the outranking method, like PROMETHEE, is the most suitable choice [67]. In this research, the PROMETHEE method was selected because, for this kind of criteria, it is much easier to define indifference and preference thresholds than to manually compare alternatives on each criterion as the AHP method does. Furthermore, the PROMETHEE method better deals with the combination of qualitative and quantitative criteria than the ELECTRE method; and criteria evaluations, in this case, do not have enough large set of data to properly construct ideal and anti-ideal alternative to the TOPSIS method. 


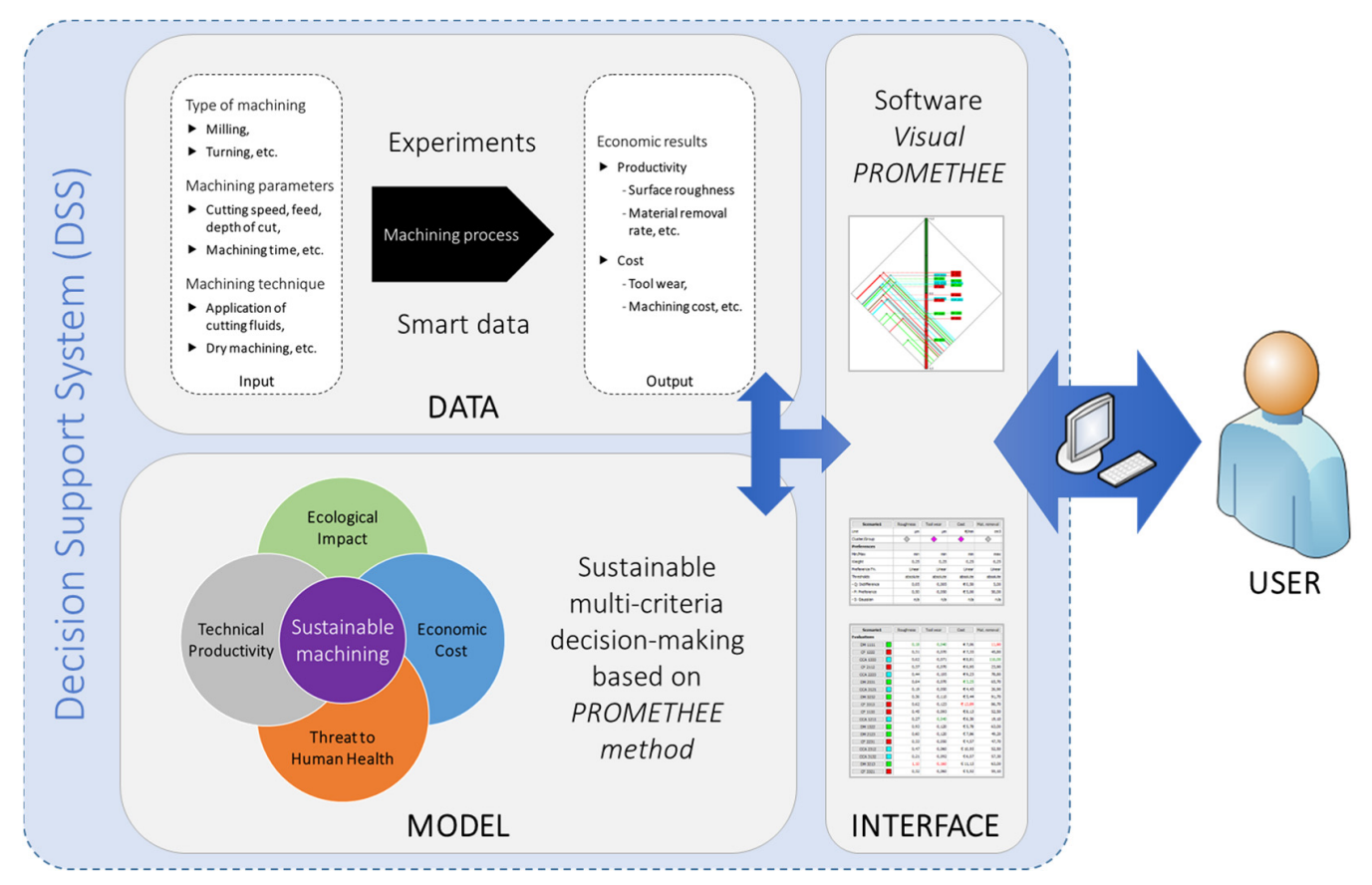

Figure 5. Proposed decision support system for smart and sustainable machining.

The PROMETHEE (Preference Ranking Organization METHod for Enrichment of Evaluations) method was developed by J.P. Brans and B. Mareschal in 1983 [68]. Input for the PROMETHEE method is a matrix consisting of a set of potential alternatives (actions) $A$, where each $a$ element of $A$ has its $f(a)$, which represents the evaluation of one criterion.

Method PROMETHEE I ranks actions by a partial ranking, with the following dominance flows, for the positive outranking flow [68]:

$$
\Phi^{+}(a)=\frac{1}{n-1} \sum_{b \in A} \Pi(a, b)
$$

and for the negative outranking flow [68]:

$$
\Phi^{-}(a)=\frac{1}{n-1} \sum_{b \in A} \Pi(b, a)
$$

where $a$ and $b$ represent the actions from a set of action $A$ (during the pairwise comparison of action $a$ with all other $n-1$ actions), $n$ is the number of actions and $\Pi$ is the aggregated preference index defined for each couple of actions.

The PROMETHEE I method gives the partial relation, and then a net outranking flow is obtained from the PROMETHEE II method, which ranks the actions by complete ranking calculating net flow [68]:

$$
\Phi(a)=\Phi^{+}(a)-\Phi^{-}(a)
$$

In the sense of priority assessment, net outranking flow represents the synthetic parameter based on defined criteria and priorities among criteria. Usually, criteria are weighted using criteria weights $w_{j}$ and the usual pondering technique [68]:

$$
\Pi(a, b)=\frac{\sum_{j=1}^{n} w_{j} P_{j}(a, b)}{\sum_{j=1}^{n} w_{j}}
$$

where $P_{j}(a, b)$ represents preference of $a$ over $b$ for a given preference function of criterion $j$. There are six different types of preference functions, but in this research, only the linear preference function with indifference and preference thresholds were used. 
As mentioned, the PROMETHEE method requires a decision matrix as an input that consists of alternatives and their criteria evaluations. In this case, alternatives are different machining techniques with different machining parameters (cutting speed, feed per tooth, depth of cut, machining time). So, five variable factors and three levels of factors were used to define the experiment set (Table 1). The experimental design proposed by Taguchi method uses the orthogonal arrays to organize the factors affecting the process, meaning the design is balanced, so that factor levels are weighted equally. Following this, every factor appears on the same number of levels, and every factor on any level will be in all combinations with other factors. Such a method allows the determination of factors that most affect the process with a minimum amount of experiments, thus saving time and resources. The levels of factors, adopted values of machining parameters correspond to the operational limits recommended by the cutting tool manufacturer together with the machine tool capabilities.

Table 1. Factors and levels used for Taguchi design of experiments [47].

\begin{tabular}{|c|c|c|c|c|c|}
\hline \multirow[t]{2}{*}{ Levels of Factor } & $\begin{array}{c}\text { Cutting Speed } \\
v_{c}[\mathrm{~m} / \mathrm{min}]\end{array}$ & $\begin{array}{c}\text { Feed Per Tooth } \\
f_{z}[\mathrm{~mm} / \mathrm{zub}]\end{array}$ & $\begin{array}{l}\text { Depth of Cut } \\
a_{e}[\mathrm{~mm}]\end{array}$ & $\begin{array}{c}\text { Machining Time } \\
t \text { [min] }\end{array}$ & $\begin{array}{c}\text { Machining Technique } \\
\qquad U_{o}\end{array}$ \\
\hline & A & B & C & D & $\mathrm{E}$ \\
\hline 1 & 100 & 0.05 & 1 & 10 & Dry milling (DM) \\
\hline 2 & 125 & 0.08 & 1.5 & 16 & $\begin{array}{l}\text { the application of cutting } \\
\text { fluids }(\mathrm{CF})\end{array}$ \\
\hline 3 & 150 & 0.11 & 2 & 22 & $\begin{array}{l}\text { Milling with the } \\
\text { application of compressed } \\
\text { cold air cooling (CCA) }\end{array}$ \\
\hline
\end{tabular}

Three levels were used, since three different machining techniques-dry milling, milling with the application of cutting fluids, milling with the application of compressed cold air cooling - were used in experiments, so three levels of parameters were defined for other factors as well.

According to Taguchi's orthogonal array, a set of 18 experiments is a minimal set for this design of experiments (Table 2). These experiments were made and four outputs (results) were measured: surface roughness, tool wear, cost, and material removal.

The profilometer Mitutoyo Surftest 301 (Mitutoyo Corporation, Kawasaki, Japan) was used for surface roughness measuring. Every measurement was repeated five times and the average value was considered. Tool wear measurements were performed in accordance with the International Standard ISO 8688-1 and periodically according to the experimental plan. Tool wear of all the cutting inserts was measured and the average value was used. This was done by using the toolmaker's microscope with 100 times magnification. Material removal was calculated by using a specific equation that considers all the important cutting and experiment parameters such as axial depth of cut, radial depth of cut, feed rate, feed per tooth, mill diameter, spindle speed and number of inserts. The costs associated with each experiment included direct labor costs (cutting tool costs, cost of cutting fluid, machining time) and electricity. The cost of electricity varied between different machining techniques.

Additionally, a label was created for each experiment based on the combination of factors (Table 2). These data were used as the input matrix for the PROMETHEE method. 
Table 2. Experiments' factors (input) and experiments' results for 18 experiments defined by Taguchi orthogonal array [47].

\begin{tabular}{|c|c|c|c|c|c|c|c|c|c|c|}
\hline \multirow[b]{2}{*}{ No. } & \multicolumn{5}{|c|}{ Factors } & \multirow[b]{2}{*}{$\begin{array}{c}\text { Label } \\
\text { (E ABCD) }\end{array}$} & \multicolumn{4}{|c|}{ Output (Result) } \\
\hline & $\mathbf{A}$ & B & $\mathrm{C}$ & D & $\mathrm{E}$ & & $\begin{array}{c}\text { Tool Wear } \\
V B[\mu \mathrm{m}]\end{array}$ & $\begin{array}{c}\text { Cost } \\
C_{s o}[€]\end{array}$ & $\begin{array}{c}\text { Surface } \\
\text { Roughnes } \\
R a[\mu \mathrm{m}]\end{array}$ & $\begin{array}{l}\text { Material } \\
\text { Removal } \\
V_{u k}[\mathrm{~cm} 3]\end{array}$ \\
\hline 1. & 1 & 1 & 1 & 1 & 1 (DM) & DM 1111 & 0.040 & 7.06 & 0.18 & 11.90 \\
\hline 2. & 1 & 2 & 2 & 2 & $2(\mathrm{CF})$ & CF 1222 & 0.070 & 7.33 & 0.31 & 45.80 \\
\hline 3. & 1 & 3 & 3 & 3 & 3 (CCA) & CCA 1333 & 0.071 & 8.81 & 0.62 & 116.00 \\
\hline 4. & 2 & 1 & 1 & 2 & $2(\mathrm{CF})$ & CF 2112 & 0.070 & 6.95 & 0.37 & 23.90 \\
\hline 5. & 2 & 2 & 2 & 3 & 3 (CCA) & CCA 2223 & 0.105 & 9.23 & 0.44 & 78.80 \\
\hline 6. & 2 & 3 & 3 & 1 & $1(\mathrm{DM})$ & DM 2331 & 0.070 & 3.25 & 0.64 & 65.70 \\
\hline 7. & 3 & 1 & 2 & 1 & 3 (CCA) & CCA 3121 & 0.050 & 4.43 & 0.19 & 26.90 \\
\hline 8. & 3 & 2 & 3 & 2 & $1(\mathrm{DM})$ & DM 3232 & 0.110 & 5.44 & 0.36 & 91.70 \\
\hline 9. & 3 & 3 & 1 & 3 & $2(\mathrm{CF})$ & CF 3313 & 0.123 & 13.89 & 0.62 & 86.70 \\
\hline 10. & 1 & 1 & 3 & 3 & $2(\mathrm{CF})$ & CF 1133 & 0.093 & 8.13 & 0.45 & 52.50 \\
\hline 11. & 1 & 2 & 1 & 1 & 3 (CCA) & CCA 1211 & 0.040 & 6.30 & 0.27 & 19.10 \\
\hline 12. & 1 & 3 & 2 & 2 & $1(\mathrm{DM})$ & DM 1322 & 0.120 & 5.78 & 0.93 & 63.00 \\
\hline 13. & 2 & 1 & 2 & 3 & 1 (DM) & DM 2123 & 0.120 & 7.86 & 0.60 & 49.20 \\
\hline 14. & 2 & 2 & 3 & 1 & $2(\mathrm{CF})$ & CF 2231 & 0.050 & 4.57 & 0.33 & 47.70 \\
\hline 15. & 2 & 3 & 1 & 2 & 3 (CCA) & CCA 2312 & 0.060 & 10.93 & 0.47 & 52.50 \\
\hline 16. & 3 & 1 & 3 & 2 & 3 (CCA) & CCA 3132 & 0.092 & 6.07 & 0.21 & 57.30 \\
\hline 17. & 3 & 2 & 1 & 3 & $1(\mathrm{DM})$ & DM 3213 & 0.160 & 11.13 & 1.10 & 63.00 \\
\hline 18. & 3 & 3 & 2 & 1 & $2(\mathrm{CF})$ & CF 3321 & 0.060 & 5.92 & 0.32 & 59.10 \\
\hline
\end{tabular}

\section{Results}

It is now time to apply the PROMETHEE method on the problem of comparison of milling techniques with different machining parameters in order to select the optimal technique and parameter set. For a start, the problem consists of 18 alternatives and 4 quantitative criteria (Figure 6). Later, the problem was extended with more criteria.

\begin{tabular}{|c|c|c|c|c|c|c|c|c|c|c|}
\hline \multicolumn{2}{|c|}{ Scenario1 } & Tool wear & Cost & Roughness & Mat. removal & Lubrication & Cooling & Chip evacuat. & Ecologic impact & Health threat \\
\hline \multicolumn{2}{|l|}{ Unit } & $\mu \mathrm{m}$ & $\epsilon / \mathrm{min}$ & $\mu \mathrm{m}$ & $\mathrm{cm} 3$ & $y / n$ & effect & effect & impact & impact \\
\hline \multicolumn{11}{|l|}{ Evaluations } \\
\hline DM 1111 & $\square$ & 0,040 & $€ 7,06$ & 0,18 & 11,90 & no & very bad & very bad & very low & very low \\
\hline DM 1322 & $\square$ & 0,120 & $€ 5,78$ & 0,93 & 63,00 & no & very bad & very bad & very low & very low \\
\hline DM 2123 & $\square$ & 0,120 & $€ 7,86$ & 0,60 & 49,20 & no & very bad & very bad & very low & very low \\
\hline DM 2331 & $\square$ & 0,070 & $€ 3,25$ & 0,64 & 65,70 & no & very bad & very bad & very low & very low \\
\hline DM 3213 & $\square$ & 0,160 & $\in 11,13$ & 1,10 & 63,00 & no & very bad & very bad & very low & very low \\
\hline DM 3232 & $\square$ & 0,110 & $€ 5,44$ & 0,36 & 91,70 & no & very bad & very bad & very low & very low \\
\hline CF 1133 & $\square$ & 0,093 & $€ 8,13$ & 0,45 & 52,50 & yes & good & very good & very high & high \\
\hline CF 1222 & $\square$ & 0,070 & $€ 7,33$ & 0,31 & 45,80 & yes & good & very good & very high & high \\
\hline CF 2112 & $\square$ & 0,070 & $€ 6,95$ & 0,37 & 23,90 & yes & good & very good & very high & high \\
\hline CF 2231 & $\square$ & 0,050 & $€ 4,57$ & 0,33 & 47,70 & yes & good & very good & very high & high \\
\hline CF 3313 & $\square$ & 0,123 & $€ 13,89$ & 0,62 & 86,70 & yes & good & very good & very high & high \\
\hline CF 3321 & $\square$ & 0,060 & $\in 5,92$ & 0,32 & 59,10 & yes & good & very good & very high & high \\
\hline CCA 1211 & $\square$ & 0,040 & $€ 6,30$ & 0,27 & 19,10 & no & very good & good & very low & very low \\
\hline CCA 1333 & $\square$ & 0,071 & $€ 8,81$ & 0,62 & 116,00 & no & very good & good & very low & very low \\
\hline CCA 2223 & $\square$ & 0,105 & $€ 9,23$ & 0,44 & 78,80 & no & very good & good & very low & very low \\
\hline CCA 2312 & $\square$ & 0,060 & $\in 10,93$ & 0,47 & 52,50 & no & very good & good & very low & very low \\
\hline CCA 3121 & $\square$ & 0,050 & $€ 4,43$ & 0,19 & 26,90 & no & very good & good & very low & very low \\
\hline CCA 3132 & $\square$ & 0,092 & $€ 6,07$ & 0,21 & 57,30 & no & very good & good & very low & very low \\
\hline
\end{tabular}

Figure 6. Input matrix with extended criteria set: 4 quantitative and 5 qualitative criteria. 
The 18 alternatives, presented in Figure 6, used the results of experiments (Table 2) as their criteria evaluations. All four criteria were quantitative criteria. 18 alternatives were divided into 3 groups: 6 alternatives represented dry machining (DM) experiments, 6 alternatives represented conventional milling experiments with the application of cutting fluids (CF), and 6 alternatives represented milling experiments with the application of compressed cold air cooling (CCA).

Three case studies are used to discuss this issue of the selection of the optimal machining technique and parameter set (Figure 6). Case 1 used 4 quantitative criteria. Case 2 extended with 3 more qualitative criteria, which represented important technical sideeffects: lubrication, cooling, and chip evacuation. Finally, Case 3 used the criteria of Case 2 plus additional ecologic and social criteria to fulfill sustainable machining criteria. Finally, an additional validation of Case 3 was made with criteria weights sensitivity analysis.

\subsection{Case 1: Comparison of Milling Techniques Based on Quantitative Economic and Productivity Criteria}

Case 1 represents a comparison of 18 different milling experiments based on 4 criteria. All criteria were quantitative, but two of them represented economic criteria (tool wear and cost) and two of them represented productivity criteria (roughness and material removal rate). Criteria evaluations of alternatives are given in Figure 6.

Figure 7 shows criteria parameters (weight, preference function type, and its parameters, etc.). Criteria weights can have a significant impact on the result, therefore equal criteria weights were given to both groups of criteria: economic criteria $50 \%$ and productivity criteria 50\%, which results in 25\% for each criterion (Figures 7 and 8).

\begin{tabular}{|c|c|c|c|c|}
\hline Scenario1 & Tool wear & Cost & Roughness & Mat. removal \\
\hline Unit & $\mu \mathrm{m}$ & $\epsilon / \min$ & $\mu \mathrm{m}$ & $\mathrm{cm} 3$ \\
\hline \multicolumn{5}{|l|}{ Cluster/Group } \\
\hline \multicolumn{5}{|l|}{ Preferences } \\
\hline Min/Max & $\min$ & $\min$ & $\min$ & $\max$ \\
\hline Weight & 0,25 & 0,25 & 0,25 & 0,25 \\
\hline Preference Fn. & Linear & Linear & Linear & Linear \\
\hline Thresholds & absolute & absolute & absolute & absolute \\
\hline -Q: Indifference & 0,005 & $€ 0,50$ & 0,05 & 5,00 \\
\hline -P: Preference & 0,050 & $€ 5,00$ & 0,50 & 50,00 \\
\hline
\end{tabular}

Figure 7. Criteria parameters and weights for Case 1.

The partial ranking by PROMETHEE I is presented in Figure 8a and shows that the first three ranked alternatives (CF 2231, CCA 3121, and CF 3321) are not completely comparable. They did not completely outrank each other, because if an alternative wants to outrank other alternatives it needs to have a higher positive flow (Phi+) and equal or lower negative flow (Phi-). However, when applying the net flow, i.e., when calculating PROMETHEE II ranking, alternative CF 2231 becomes the 1st ranked alternative (Figure 8b,c).

When analyzing the ranking, it became clear that this problem has some issues to solve. Namely, when looking at the first five ranked alternatives (Figure 8c): two of them were CF alternatives, one is a CCA alternative, and two are DM alternatives. The rest of the ranking shows the chaotic distribution of alternatives, as well. Therefore, it is clear that something is missing to produce a more stable comparison and ranking, and what is missing are some additional criteria that will enable proper comparison of machining techniques. 


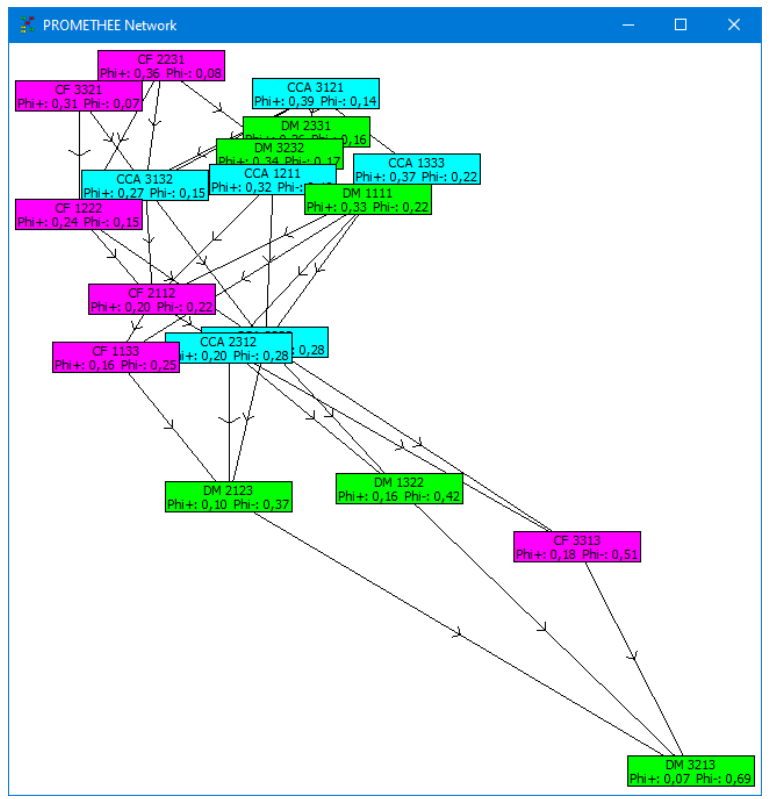

(a)

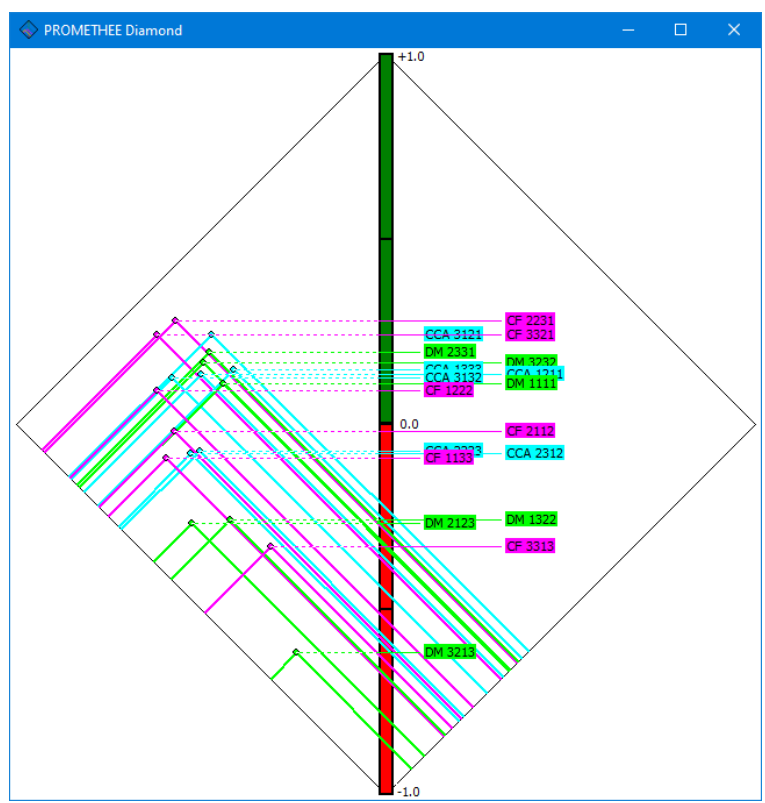

(b)

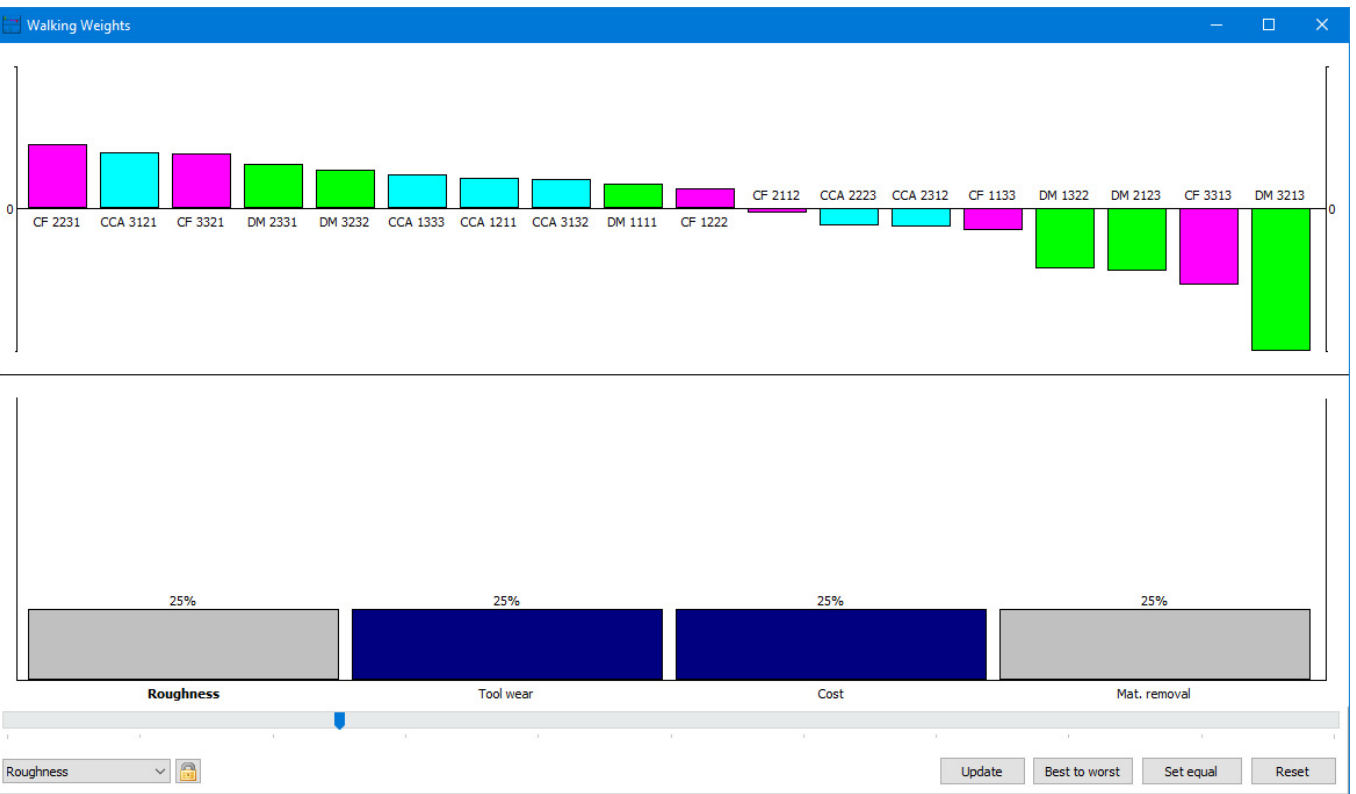

(c)

Figure 8. Case 1: (a) PROMETHEE I partial ranking of alternatives; (b) PROMETHEE II complete ranking of alternatives; (c) Distribution of criteria weights and ranking of alternatives (left to right: the best to the worst).

3.2. Case 2: Comparison of Milling Techniques Based on Quantitative and Qualitative Economic, and Productivity Criteria

Case 2 represents a comparison of 18 different milling experiments based on 7 criteria. The first four criteria were quantitative criteria, the same as in Case 1, but three additional qualitative criteria were added to the group of productivity criteria: lubrication, cooling and chip evacuation. These qualitative criteria better-described alternatives depending on the machining technique. Namely, lubrication had a good effect on the reduction of the tool wear during the machining process and was the only technique that provides lubrication in the application of cutting fluids (CF). Both application of cutting fluids (CF) and application 
of compressed cold air (CCA) provided cooling, but, CCA provided better cooling since the cold air was used, and cutting fluids were not cooled. Finally, chip evacuation was better with the application of cutting fluids (CF) than the application of compressed cold air (CCA), and dry machining (DM) had poor chip evacuation and cooling. It is clear that it is not easy to define proper quantitative descriptions of these criteria, so a qualitative description is used. The group of experts (mechanical engineers) were decision-makers that defined the qualitative evaluations of alternatives for these criteria. A 5-point Likert scale was used, so it was not hard to define these evaluations, but it is not so precise, as well. A more precise qualitative scale or quantitative description of these criteria will be the subject of future research.

Criteria evaluations of alternatives can be found in part of a matrix presented in Figure 6. Figure 9 shows criteria parameters (weight, preference function type, and its parameters, etc.), and, again, equal criteria weights were given to both groups of criteria: economic criteria $50 \%$ and productivity criteria $50 \%$, which results with $25 \%$ for each of economic criteria and 10\% for each of productivity criteria (Figures 9 and 10).

\begin{tabular}{|c|c|c|c|c|c|c|c|}
\hline Scenario1 & Tool wear & Cost & Roughness & Mat. removal & Lubrication & Cooling & Chip evacuat. \\
\hline Unit & $\mu \mathrm{m}$ & $\epsilon / \min$ & $\mu \mathrm{m}$ & $\mathrm{cm} 3$ & $y / n$ & effect & effect \\
\hline Cluster/Group & & & $\diamond$ & $\nabla$ & $\diamond$ & $\diamond$ & $\nabla$ \\
\hline \multicolumn{8}{|l|}{ Preferences } \\
\hline Min/Max & $\min$ & $\min$ & $\min$ & $\max$ & $\max$ & $\max$ & $\max$ \\
\hline Weight & 0,25 & 0,25 & 0,10 & 0,10 & 0,10 & 0,10 & 0,10 \\
\hline Preference Fn. & Linear & Linear & Linear & Linear & Linear & Linear & Linear \\
\hline Thresholds & absolute & absolute & absolute & absolute & absolute & absolute & absolute \\
\hline -Q: Indifference & 0,005 & $€ 0,50$ & 0,05 & 5,00 & 0,00 & 0,00 & 0,00 \\
\hline -P: Preference & 0,050 & $€ 5,00$ & 0,50 & 50,00 & 1,00 & 4,00 & 4,00 \\
\hline
\end{tabular}

Figure 9. Criteria parameters and weights for Case 2.

The partial ranking by PROMETHEE I is presented in Figure 10a, and shows that the 1st ranked alternative CF 2231 dominated above all other alternatives. The ranking by PROMETHEE II was more stable, since the DM alternatives were pushed to the bottom of the rank (Figure 10b,c). Now, the distribution of the first five ranked alternatives consisted of three CF alternatives and two CCA alternatives, and the best ranked DM alternative had 9th rank.

However, it is not clear from Figure 10 why this approach to the problem is more stable than the approach of Case 1. But, an additional look at GAIA (Geometrical Analysis for Interactive Aid) planes, which represent the projection of all criteria axes and alternatives on a single plane, can help to resolve this. Figure 11a represents the GAIA plot of the problem from Case 1, and it is completely chaotic with CF, CCA, and DM alternatives mutually mixed on the plane. 


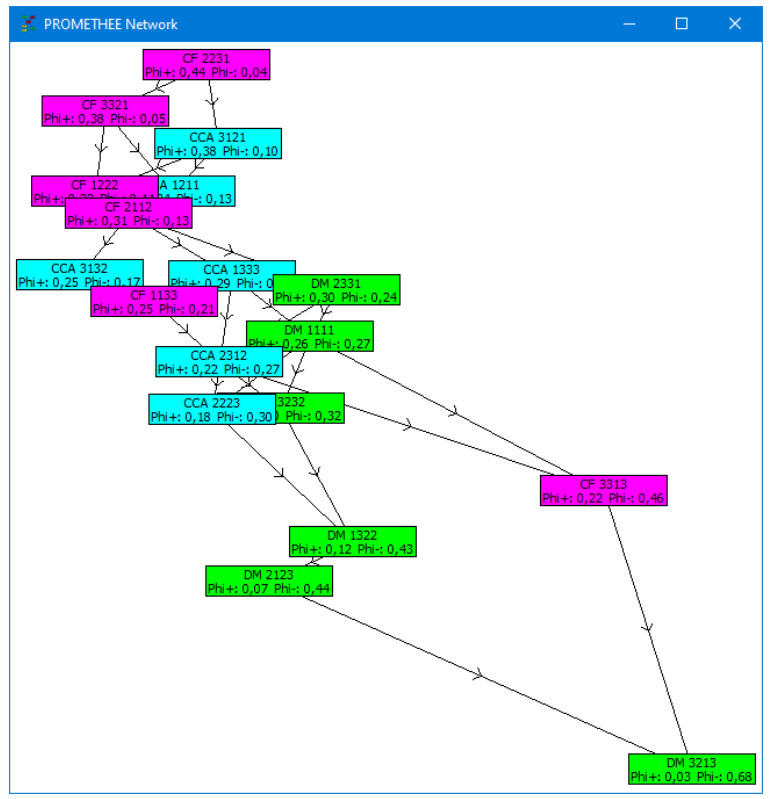

(a)

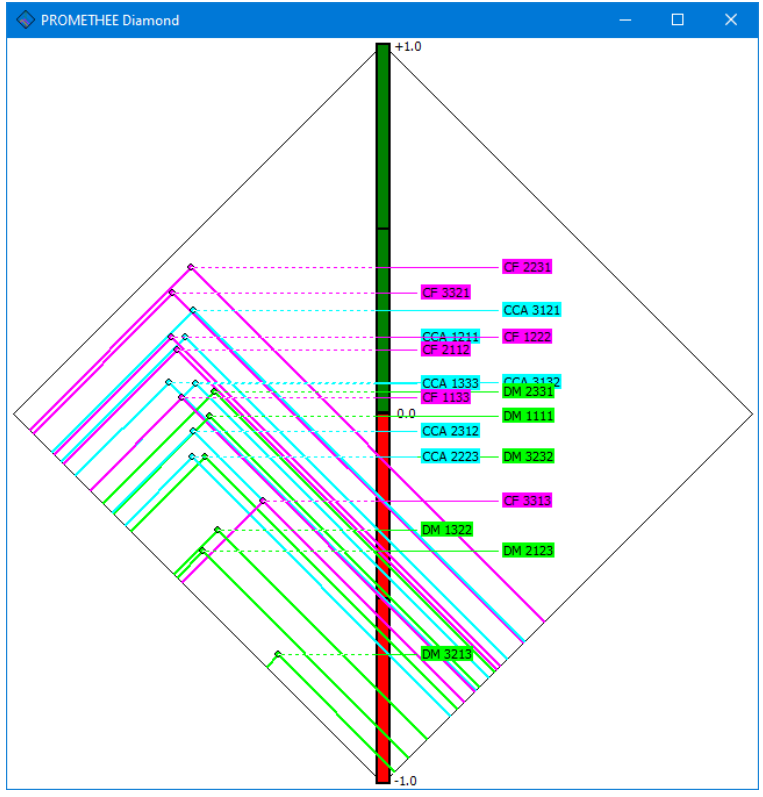

(b)

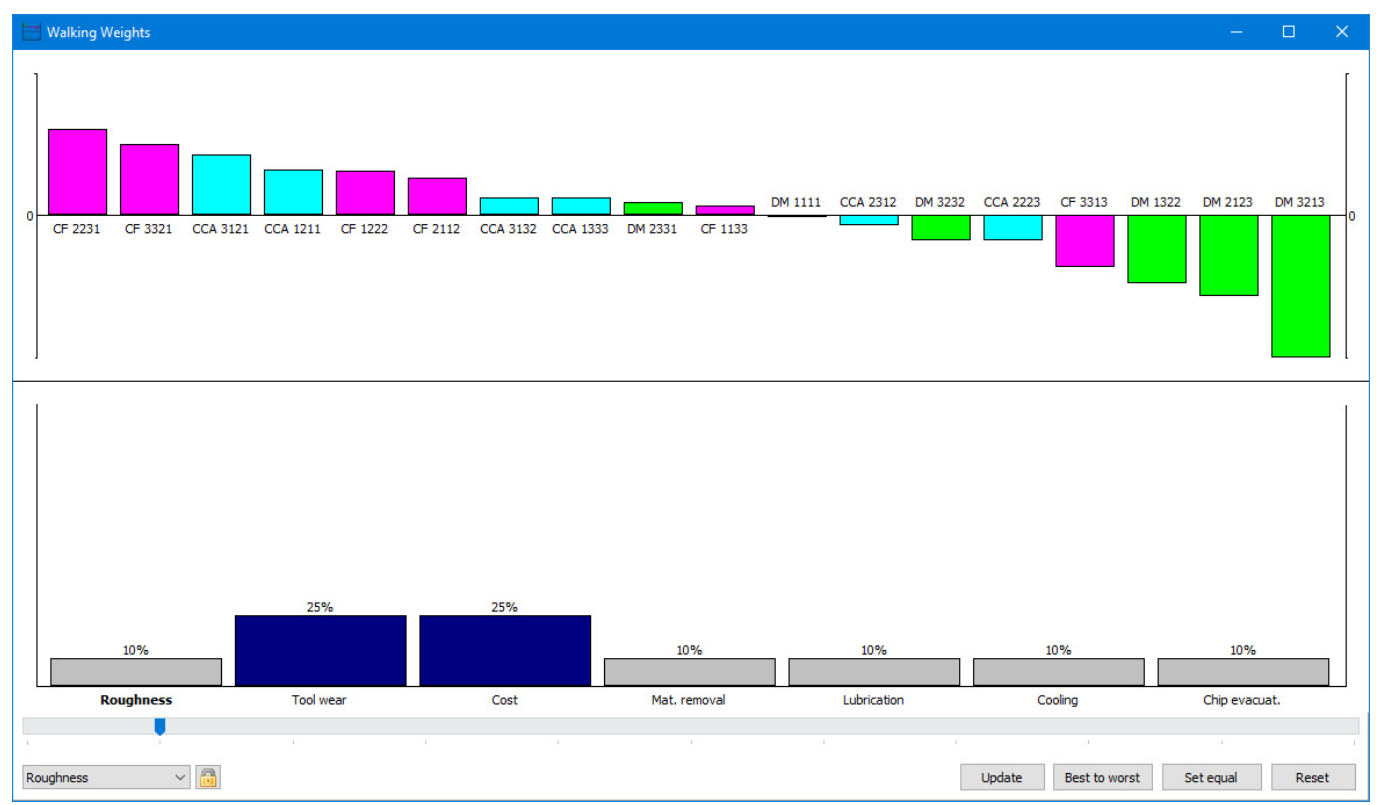

(c)

Figure 10. Case 2: (a) PROMETHEE I partial ranking of alternatives; (b) PROMETHEE II complete ranking of alternatives; (c) distribution of criteria weights and ranking of alternatives (left to right: the best to the worst).

The situation is different in Figure 11b, which represents the GAIA plot of the problem from Case 2. The GAIA plot of Case 2 shows three different clusters: CF alternatives cluster, CCA alternatives cluster, and DM alternatives cluster. So it can be concluded that Case 2 is a better approach to this problem than Case 1, however, Case 2 did not meet the sustainability criteria presented in Figure 4, therefore an additional case was needed. 


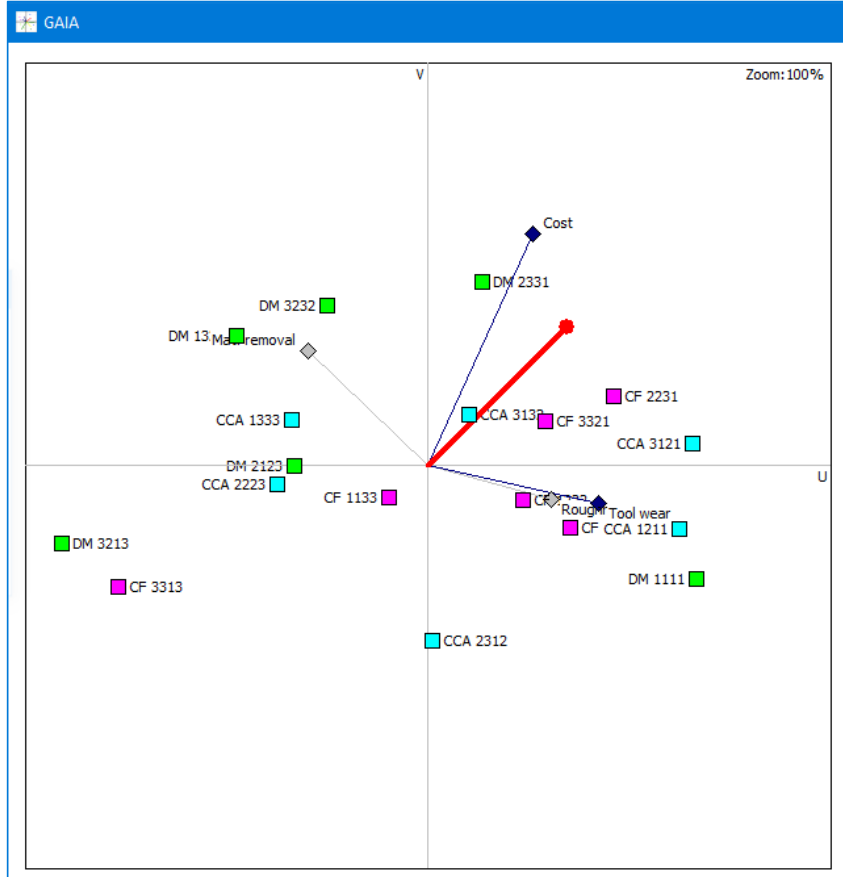

(a)

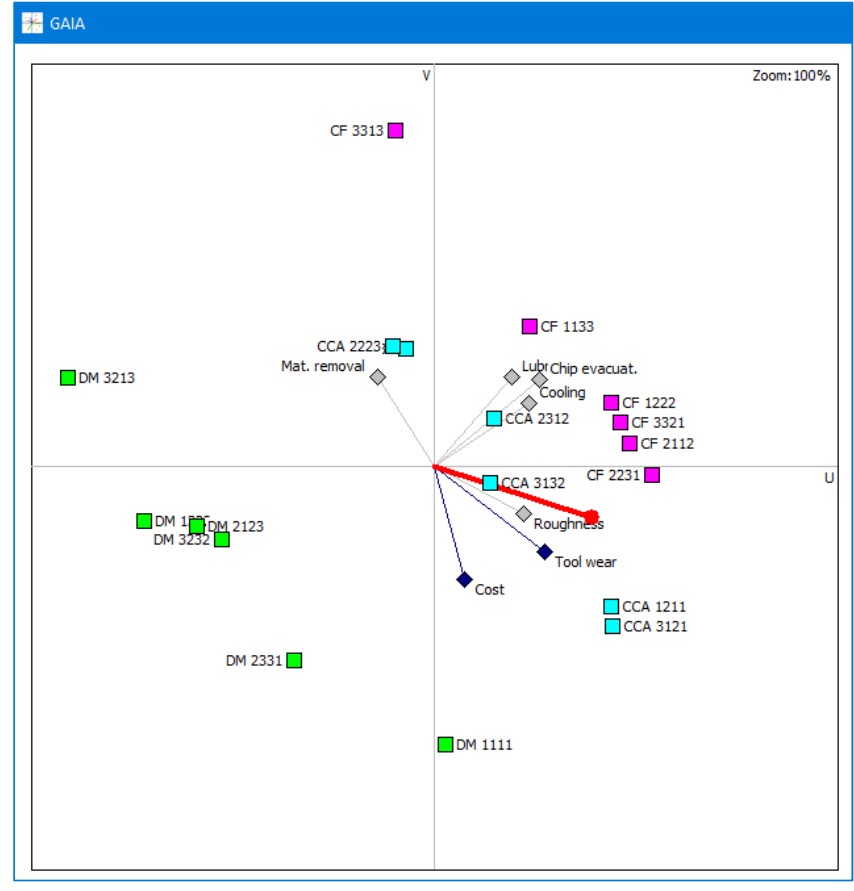

(b)

Figure 11. Comparison of Case 1 and 2: (a) the GAIA plot of the problem from Case 1; (b) the GAIA plot of the problem from Case 2.

\subsection{Case 3: Comparison of Milling Techniques Based on Sustainability: Economic, Productivity,} Ecologic, and Social Criteria

Finally, Case 3 is a comparison of 18 different milling experiments based on sustainability criteria: economic ( 2 criteria), productivity ( 5 criteria), ecologic ( 1 criterion) and social ( 1 criterion). The first seven criteria were economic and productivity criteria, the same as in Case 2, but additionally ecologic (ecologic impact) and social (health threat) criteria were added. Ecologic impact represents a negative impact on the environment that $\mathrm{CF}$ alternatives have because of the cutting fluids that need to be processed and disposed of. Health threat represents the threat of the technique to human health and, again, CCA and DM do not represent a threat, but CF represents a serious threat because a worker's skin can be in contact with cutting fluids and there is a problem of cutting fluids' aerosol.

Criteria evaluations of alternatives are presented in Figure 6. Figure 12 shows the criteria parameters (weight, preference function type, and its parameters, etc.), and, again, equal criteria weights were given to all criteria groups: economic criteria $25 \%$, productivity criteria $25 \%$, ecologic criteria $25 \%$, and social criteria $25 \%$, which results in $12.5 \%$ for each of economic criteria, $5 \%$ for each of productivity criteria, $25 \%$ for ecologic criterion, and $25 \%$ for social criterion (Figures 12 and 13 ).

\begin{tabular}{|c|c|c|c|c|c|c|c|c|c|}
\hline Scenario1 & Tool wear & Cost & Roughness & Mat. removal & Lubrication & Cooling & Chip evacuat. & Ecologic impact & Health threat \\
\hline Unit & $\mu \mathrm{m}$ & $\epsilon / \min$ & $\mu \mathrm{m}$ & $\mathrm{cm} 3$ & $y / n$ & effect & effect & impact & impact \\
\hline Cluster/Group & & & $\diamond$ & $\diamond$ & $\diamond$ & $\diamond$ & $\diamond$ & 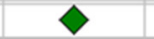 & \\
\hline \multicolumn{10}{|l|}{$\begin{array}{l}\text { Cluster/Group } \\
\text { Preferences }\end{array}$} \\
\hline $\operatorname{Min} / \operatorname{Max}$ & $\min$ & $\min$ & $\min$ & $\max$ & $\max$ & $\max$ & $\max$ & $\min$ & $\min$ \\
\hline Weight & 0,13 & 0,13 & 0,05 & 0,05 & 0,05 & 0,05 & 0,05 & 0,25 & 0,25 \\
\hline Preference Fn. & Linear & Linear & Linear & Linear & Linear & Linear & Linear & Linear & Linear \\
\hline Thresholds & absolute & absolute & absolute & absolute & absolute & absolute & absolute & absolute & absolute \\
\hline - Q: Indifference & 0,005 & $€ 0,50$ & 0,05 & 5,00 & 0,00 & 0,00 & 0,00 & 0,00 & 0,00 \\
\hline -P: Preference & 0,050 & $€ 5,00$ & 0,50 & 50,00 & 1,00 & 4,00 & 4,00 & 4,00 & 4,00 \\
\hline
\end{tabular}

Figure 12. Criteria parameters and weights for Case 3. 


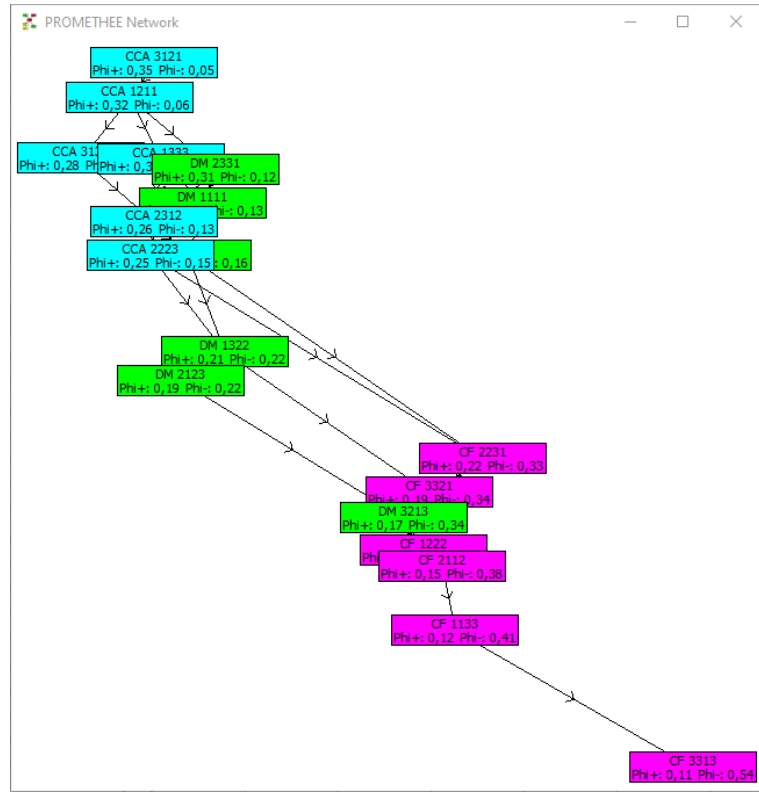

(a)

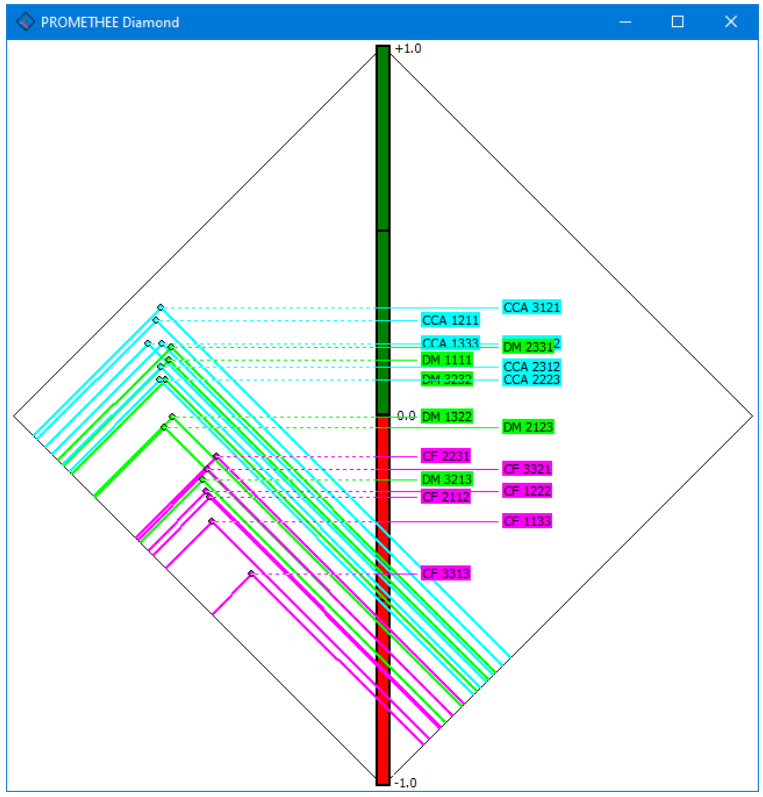

(b)

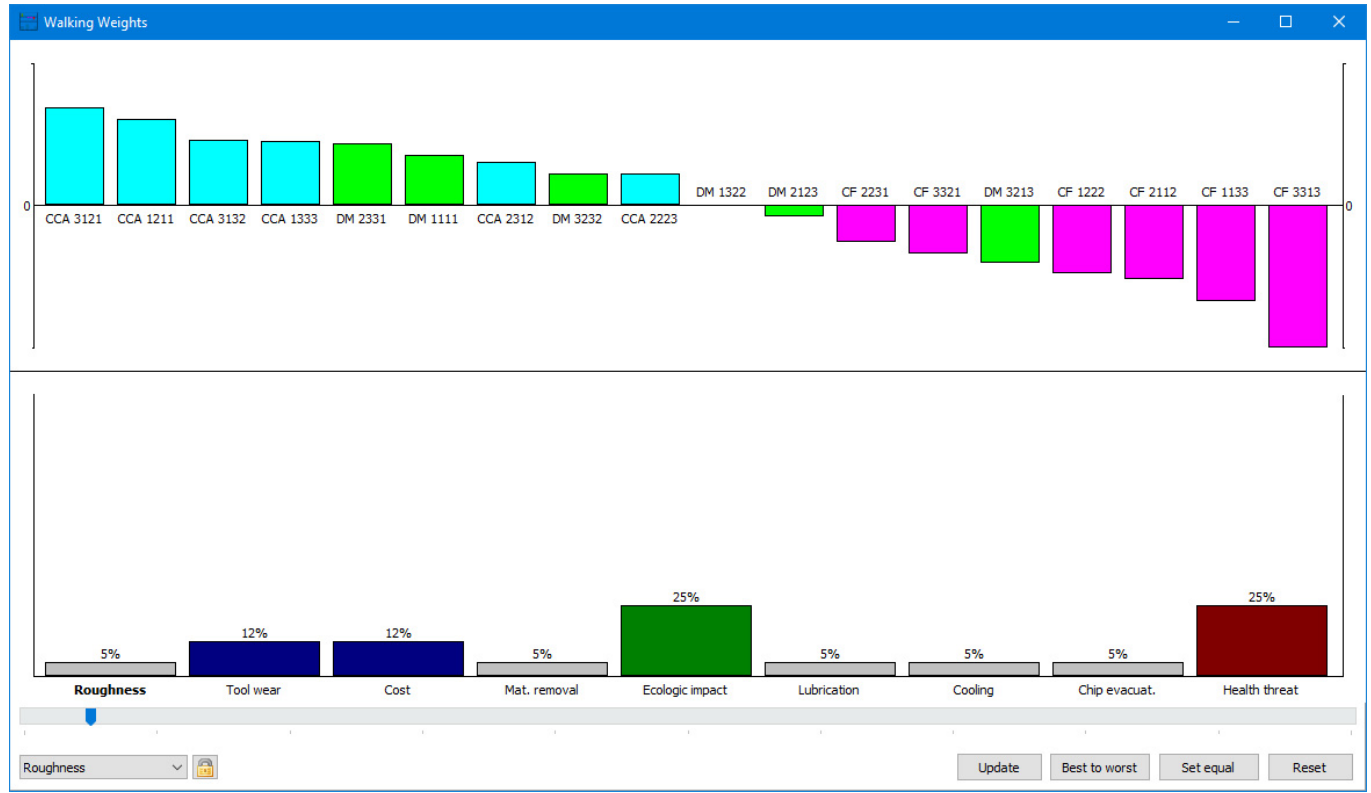

(c)

Figure 13. Case 3: (a) PROMETHEE I partial ranking of alternatives; (b) PROMETHEE II complete ranking of alternatives; (c) distribution of criteria weights and ranking of alternatives (left to right: the best to the worst).

The partial ranking by PROMETHEE I is presented in Figure 13a and shows that the 1st ranked alternative CCA 3121 dominates over the 2nd ranked alternative CCA 1211, and both of them dominate above all other alternatives. The ranking by PROMETHEE II shows complete domination of green technologies CCA and DM over CF technology (Figure 13b,c). Finally, the distribution of the first five ranked alternatives consists of the green technologies only: four CCA alternatives and one DM alternatives, and the best ranked $\mathrm{CF}$ alternative has 12 th rank.

Furthermore, the GAIA plot indicates a stable problem and three different machining techniques are forming three different clusters of alternatives (Figure 14). 


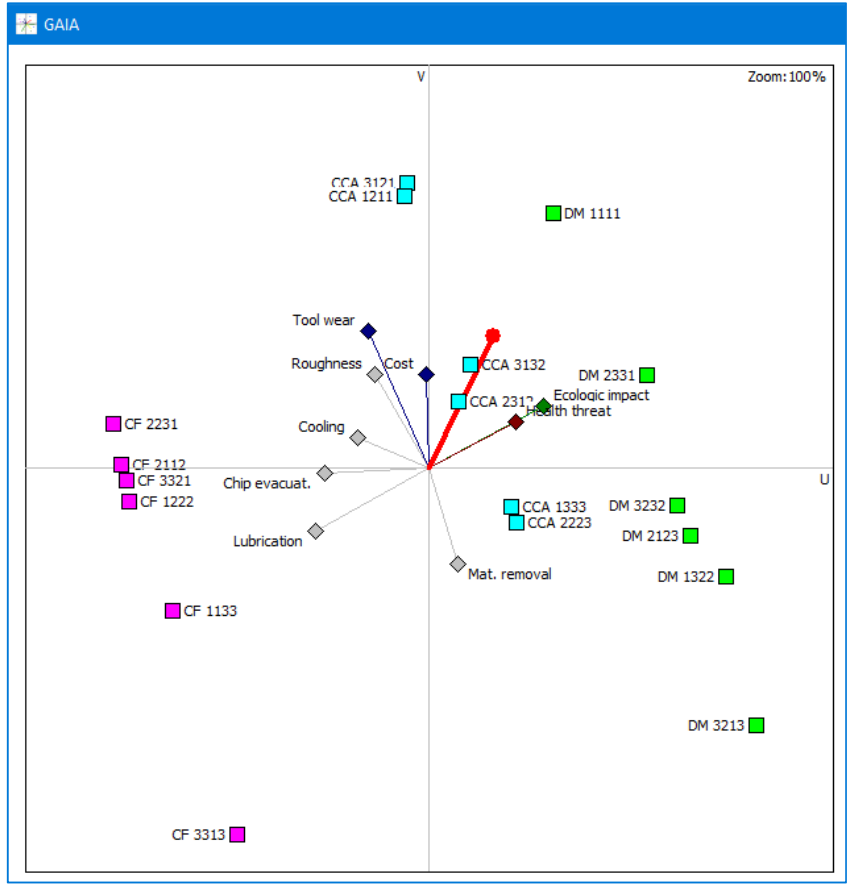

Figure 14. The GAIA plot of the problem from Case 3.

This case demonstrated the importance of using sustainability criteria that include ecologic and social criteria. Only in this case, the non-green cutting fluids machining technique did not get a high rank and would not be selected as a milling option.

\subsection{Sustainability Criteria Weights Sensitivity Analysis}

Before the final conclusion, some kind of validation of the sustainability-criteriabased approach (Case 3) must be made. A validation was made through criteria weights sensitivity analysis. An analysis was based on the determination of the criterion weight interval in which the rankings of the selected number of alternatives remained the same. An example of this analysis is given in Figure 15.

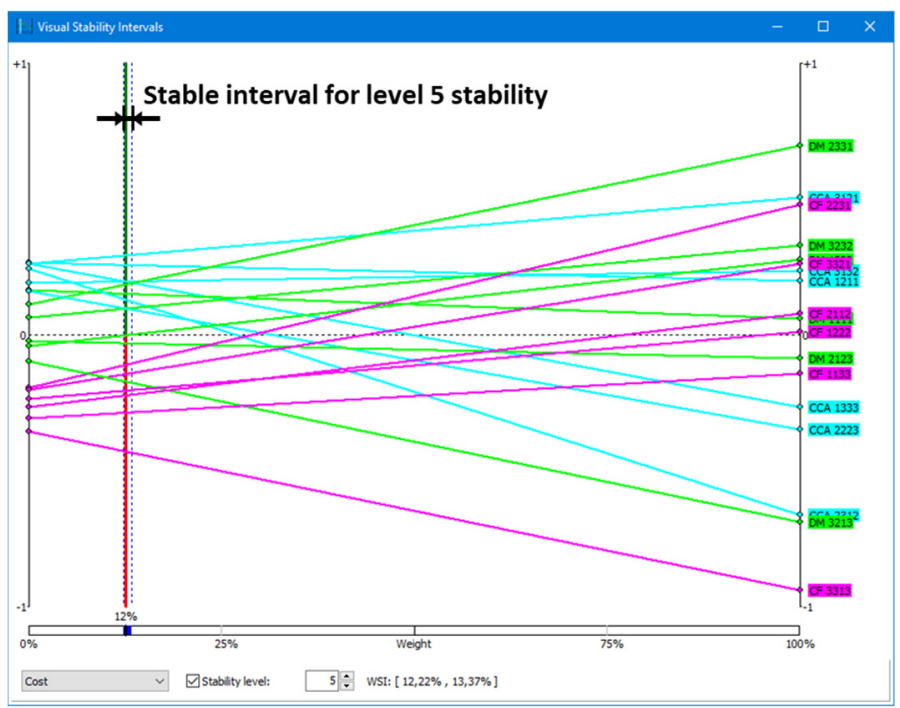

(a)

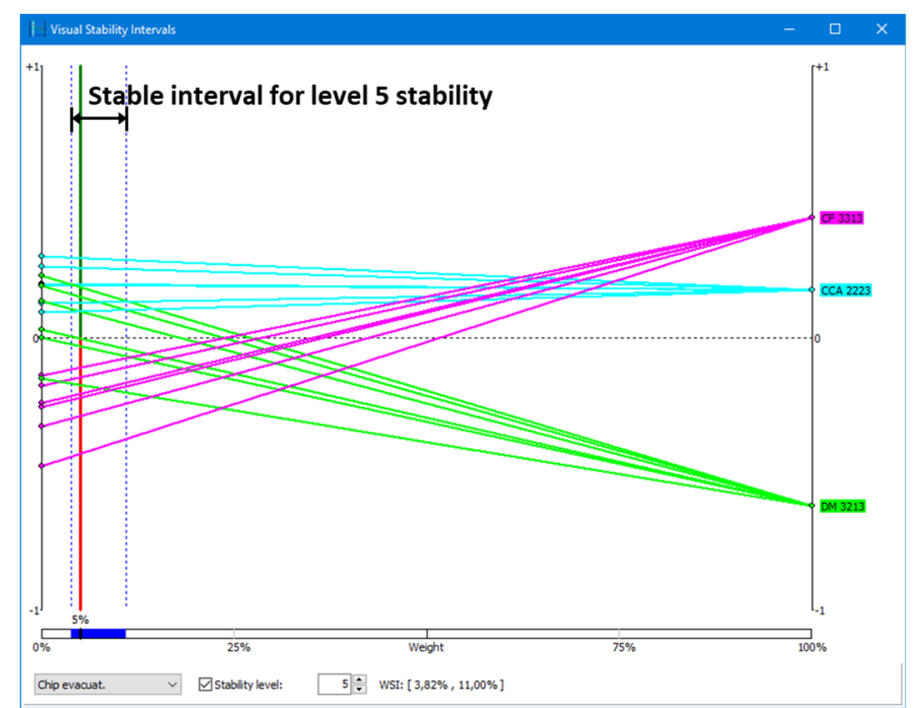

(b)

Figure 15. Comparison of stability intervals: (a) Stability interval (level 5) for criterion Cost; (b) Stability interval (level 5) for criterion Chip evacuation. 
The level 5 stability was selected and it implied the weight interval in which the ranking of the first five alternatives was not changing. Other alternatives were perhaps swapping their ranks, but the ranking of the first five alternatives remains the same.

Figure 15a represents a stable interval for criterion Cost, and its weight is not so stable. Namely, criterion Cost had a weight of $12.5 \%$, and it could have any weight between 12.22 and $13.37 \%$, in order to keep the same order of the first five ranked alternatives. But, it was a very narrow interval compared to the interval of criterion Chip evacuation (Figure 15b), which was between 3.82 and $11 \%$. Therefore, the weight interval of criterion Cost was actually unstable and the interval of criterion Chip evacuation was stable.

To validate this case, by checking the changes in ranking with the change of the criteria weights, a different set of criteria weights should be given. A common approach is to use equal weights, but not equal weights of criteria groups, but an equal weight of each criterion. In order to do so, all criteria weights were set to $11.1 \%$. The results are given in Figure 16.

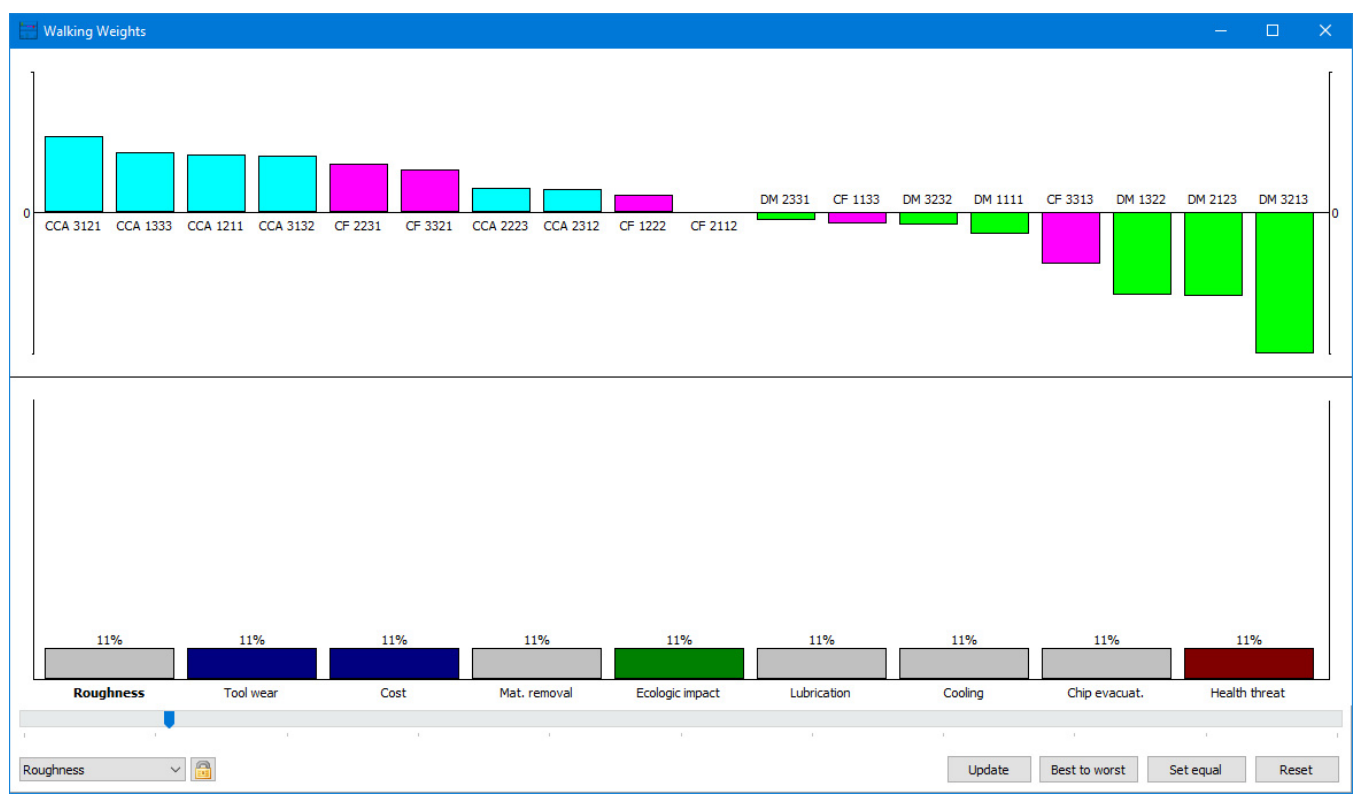

Figure 16. Distribution of criteria weights and ranking of alternatives for equal weights.

Figure 16 shows that, even in the case of equal weights, the green CCA technique with four best-ranked alternatives (CCA 3121, CCA 1333, CCA 1211, and CCA 3132) kept the lead over the non-green CF technique. Furthermore, CCA 3121 was the 1st ranked alternative in Case 3, as well. DM techniques, which were in the middle of the rank in Case 3, were at the bottom now. The reason is that DM alternatives have poor performance in terms of lubrication and cooling, which now had higher weights. To conclude, the validation of the sustainability-criteria-based approach has confirmed the approach, and also confirmed the advantages of the green CCA machining technique.

The criteria weights are the important issue and the analysis of different criteria sets, i.e., scenarios, definitely represent one of the most important aspects for future research. In this research, the same weight was used for each of four criteria groups: economic, productivity, ecologic, and social criteria. Of course, it would be interesting to see how different weights of these criteria groups affect the result. But criteria weights for the machining process cannot be defined randomly or approximately, so it represents a significant research issue, as presented by Kumar et al. [69]. The most common approaches are based on the usage of AHP method to mutually compare the importance of criteria and calculate their weights using the AHP procedure [70], or based on EWM (entropy weights method) that uses probability theory to compute uncertain information [71,72]. Both of the approaches will be considered for future research on this topic. 


\section{Conclusions}

In this research, the decision support system was developed to support the selection of machining techniques and their parameters by taking the sustainability criteria into account. Three cases have been analyzed (Case 1,2, and 3) to demonstrate the need and the importance of using sustainability criteria that include ecologic and social criteria. Case 1 and 2 used economic and productivity criteria only, and in both cases, the non-green cuttingfluids-based techniques got very high ranks. However, when ecologic and social criteria were added in Case 3, the green dry-machining-based and compressed-cold-air-based techniques achieved the highest ranks and suppressed cutting-fluids-based techniques towards the bottom. This kind of approach should be imperative: productivity cannot be maximized at the expense of the environment and human health. At the moment, and perhaps it will always remain that way, the problem is that the conventional cuttingfluids-based machining is more productive and more economical than green machining. So, the question is why should we invest in green machining techniques? Because it is investing in the future generations, so they could live in the same natural environment as present generations. However, a radical change in a mindset is needed to accept that fact, especially in managerial thinking. Nevertheless, the negative impact on the environment and human health can also be seen as an economical cost, although it is not easy to make such a calculation. If seen from that perspective, investing in green technologies reduces the economic cost of manufacturing. So, it is the change of the perspective that management and everybody else must accept. This research at least somehow contributes to that change. The main goal of further research will be the application of the developed approach and DSS to other machining and manufacturing processes, as well.

Author Contributions: Conceptualization, L.C. and M.M.; methodology, L.C. and M.M.; software, M.M.; validation, L.C., M.M., N.G. and M.C.Z.; writing-original draft preparation, L.C. and M.M.; writing-review and editing, L.C., M.M., N.G. and M.C.Z. All authors have read and agreed to the published version of the manuscript.

Funding: The publishing of this research was funded by the MZO-VIF INTEMON project.

Institutional Review Board Statement: Not applicable.

Informed Consent Statement: Not applicable.

Acknowledgments: Experimental data sets used in this research are from Luka Celent's doctoral dissertation, which was part of the MZOS 023-0692976-1742 research project.

Conflicts of Interest: The authors declare no conflict of interest.

\section{References}

1. King, N.; Keranen, L.; Gunter, K.; Sutherland, J. Wet Versus Dry Turning: A Comparison of Machining Costs, Product Quality, and Aerosol Formation. SAE Tech. Pap. 2001, 2001, 11. [CrossRef]

2. Kahle, L.R.; Gurel-Atay, E. Communicating Sustainability for the Green Economy, 1st ed.; Routledge: New York, NY, USA, 2014.

3. The United Nations. The 17 Sustainable Development Goals. Available online: https://sdgs.un.org/goals (accessed on 7 September 2021).

4. The Holy See, Encyclical Letter Laudato Si' of the Holy Father Francis on Care for Our Common Home. Available online: https: //www.vatican.va/content/francesco/en/encyclicals/documents/papa-francesco_20150524_enciclica-laudato-si.html (accessed on 7 September 2021).

5. Khan, A.M.; Anwar, S.; Gupta, M.K.; AlFaify, A.; Hasnain, S.; Jamil, M.; Mia, M.; Pimenov, D.Y. Energy-Based Novel Quantifiable Sustainability Value Assessment Method for Machining Processes. Energies 2020, 13, 6144. [CrossRef]

6. Jamwal, A.; Agrawal, R.; Sharma, M.; Kumar, A.; Luthra, S.; Pongsakornrungsilp, S. Two decades of research trends and transformations in manufacturing sustainability: A systematic literature review and future research agenda. Prod. Eng. 2021, 1-25. [CrossRef]

7. $\quad$ Byers, J.P. Metalworking Fluids, 3rd ed.; CRC Press: Boca Raton, FL, USA, 2017.

8. Glenn, T.; Van Antwerpen, F. Opportunities and Market Trend in Metalworking Fluids. J. Soc. Tribol. Lubr. Eng. 2004, 54, 31-34.

9. Abdala, H.S.; Baines, W.; McIntyre, G.; Slade, C. Development of novel sustainable neat-oil metal working fluids for stain-less steel and titanium alloy machining. Part 1. Formul. Dev. Int. J. Adv. Manuf. Technol. 2007, 34, 21-33. [CrossRef] 
10. Debnath, S.; Reddy, M.M.; Yi, Q.S. Environmental friendly cutting fluids and cooling techniques in machining: A review. J. Clean. Prod. 2014, 83, 33-47. [CrossRef]

11. Young, P.; Byrne, G.; Cotterell, M. Manufacturing and the environment. Int. J. Adv. Manuf. Technol. 1997, 13, 488-493. [CrossRef]

12. Byrne, G.; Dornfeld, D.; Denkena, B. Advancing Cutting Technology. CIRP Ann. 2003, 52, 483-507. [CrossRef]

13. Soković, M.; Mijanović, K. Ecological aspects of the cutting fluids and its influence on quantifiable parameters of the cutting processes. J. Mater. Process. Technol. 2001, 109, 181-189. [CrossRef]

14. United States Environmental Protection Agency. National Occupational Exposure Survey (NOES). Available online: https: / / cfpub.epa.gov/si/si_public_record_Report.cfm?Lab=OEI\&dirEntryID=132500 (accessed on 29 December 2021).

15. Ueno, S.; Shiomi, Y.; Yokota, K. Metalworking Fluid Hand Dermatitis. Ind. Health 2002, 40, 291-293. [CrossRef]

16. Mackerer, C.R. Health Effects of Oil Mists: A Brief Review. Toxicol. Ind. Health 1989, 5, 429-440. [CrossRef]

17. Thorne, P.S.; DeKoster, J.A.; Subramanian, P. Environmental Assessment of Aerosols, Bioaerosols, and Airborne Endotoxins in a Machining Plant. Am. Ind. Hyg. Assoc. J. 1996, 57, 1163-1167. [CrossRef]

18. Bartz, W.J. Lubricants and the environment. Tribol. Int. 1998, 31, 35-47. [CrossRef]

19. Davim, J.P. Machining: Fundamentals and Recent Advances, 2008th ed.; Springer: Berlin/Heidelberg, Germany, 2008.

20. Katna, R.; Suhaib, M.; Agrawal, N. Nonedible vegetable oil-based cutting fluids for machining processes-A review. Mater. Manuf. Process. 2020, 35, 1-32. [CrossRef]

21. Pusavec, F.; Kramar, D.; Krajnik, P.; Kopac, J. Transitioning to sustainable production—Part II: Evaluation of sustainable machining technologies. J. Clean. Prod. 2010, 18, 1211-1221. [CrossRef]

22. Kaynak, Y.; Gharibi, A. Progressive Tool Wear in Cryogenic Machining: The Effect of Liquid Nitrogen and Carbon Dioxide. J Manuf. Mater. Process. 2018, 2, 31. [CrossRef]

23. Breque, M.; De Nul, L.; Petridis, A. Industry 5.0-Towards a Sustainable, Human-Centric and Resilient European Industry; Publications Office of the European Union: Luxembourg, 2021.

24. Müller, J. Enabling Technologies for Industry 5.0-Results of a Workshop with Europe's Technology Leaders; Publications Office of the European Union: Luxembourg, 2020.

25. Kagermann, H.; Wahlster, W.; Helbig, J. Recommendations for Implementing the Strategic Initiative Industrie 4.0; Heilmeyer und Sernau: Berlin, Germany, 2013.

26. Vacchi, M.; Siligardi, C.; Cedillo-González, E.I.; Ferrari, A.M.; Settembre-Blundo, D. Industry 4.0 and Smart Data as Enablers of the Circular Economy in Manufacturing: Product Re-Engineering with Circular Eco-Design. Sustainability 2021, $13,10366$. [CrossRef]

27. Enyoghasi, C.; Badurdeen, F. Industry 4.0 for sustainable manufacturing: Opportunities at the product, process, and system levels. Resour. Conserv. Recycl. 2021, 166, 105362. [CrossRef]

28. Gupta, K. A Review on Green Machining Techniques. Procedia Manuf. 2020, 51, 1730-1736. [CrossRef]

29. Sreejith, P.S.; Ngoi, B.K.A. Dry machining: Machining of the future. J. Mater. Process. Technol. 2000, 101, 287-291. [CrossRef]

30. Dudzinski, D.; Devillez, A.; Moufki, A.; Larrouquère, D.; Zerrouki, V.; Vigneau, J. A review of developments towards dry and high speed machining of Inconel 718 alloy. Int. J. Mach. Tools Manuf. 2004, 44, 439-456. [CrossRef]

31. Dinnie, K. Creating Corporate Reputations, Identity, Image, and Performance. Eur. J. Mark. 2003, 37, $114-147$.

32. Naveed, M.; Arslan, A.; Javed, H.M.A.; Manzoor, T.; Quazi, M.M.; Imran, T.; Zulfattah, Z.M.; Khurram, M.; Fattah, I.M.R. State-of-the-Art and Future Perspectives of Environmentally Friendly Machining Using Biodegradable Cutting Fluids. Energies 2021, 14, 4816. [CrossRef]

33. Braga, D.U.; Diniz, A.E.; Miranda, G.W.A.; Coppini, N.L. Using a Minimum Quantity of Lubricant (MQL) and a Diamond Coated Tool in The Drilling of Aluminium-silicon Alloys. J. Mater. Processing Technol. 2002, 122, 127-138. [CrossRef]

34. Dixit, U.S.; Sarma, D.K.; Davim, J.P. Environmentally Friendly Machining, 2012th ed.; Springer: New York, NY, USA, 2012.

35. Su, Y.; He, N.; Li, A.; Iqbal, A.; Xiao, H.A.; Xu, S.; Qui, B.G. Refrigerated cooling air cutting of difficult-to-cut materials. Inter-Natl. J. Mach. Tools Manuf. 2007, 47, 927-933. [CrossRef]

36. Sharma, V.S.; Dogra, M.; Suri, N. Cooling techniques for improved productivity in turning. Int. J. Mach. Tools Manuf. 2009, 49, 435-453. [CrossRef]

37. Hilsch, R. The Use of the Expansion of Gases in a Centrifugal Field as Cooling Process. Rev. Sci. Instrum. 1947, 18, 108-113. [CrossRef]

38. Aronson, R.B. Vortex tube: Cooling with compressed air. Mach. Des. 1996, 48, 140-143.

39. Pinar, A.M.; Uluer, O.; Kirmaci, V. Optimization of counter flow Ranque-Hilsch vortex tube performance using Taguchi method. Int. J. Refrig. 2009, 32, 1487-1494. [CrossRef]

40. Rahman, M.; Kumar, A.S.; Salam, M.U.; Ling, M.S. Effect of Chilled Air on Machining Performance in End Milling. Int. J. Adv. Manuf. Technol. 2003, 21, 787-795. [CrossRef]

41. Yalçın, B.; Özgür, A.; Koru, M. The effects of various cooling strategies on surface roughness and tool wear during soft materials milling. Mater. Des. 2009, 30, 896-899. [CrossRef]

42. Timmerhaus, K.D.; Reed, R.P. Cryogenic Engineering, 1st ed.; Springer: New York, NY, USA, 2007.

43. Shokrani, A.; Dhokia, V.; Newman, S. Environmentally conscious machining of difficult-to-machine materials with regard to cutting fluids. Int. J. Mach. Tools Manuf. 2012, 57, 83-101. [CrossRef] 
44. De Chiffre, L.; Andreasen, J.; Lagerberg, S.; Thesken, I.-B. Performance Testing of Cryogenic $\mathrm{CO}_{2}$ as Cutting Fluid in Parting/Grooving and Threading Austenitic Stainless Steel. CIRP Ann. 2007, 56, 101-104. [CrossRef]

45. Kumar, K.K.; Choudhury, S. Investigation of tool wear and cutting force in cryogenic machining using design of experiments. $J$ Mater. Process. Technol. 2008, 203, 95-101. [CrossRef]

46. Pei, H.J.; Zheng, W.J.; Wang, G.C.; Wang, H.Q. Application of Biodegradable Cutting Fluids in High Speed Turning. Adv. Mater. Res. 2011, 381, 20-24. [CrossRef]

47. Celent, L. Implementation of Compressed Cold Air Using Vortex Tube in Milling Process [Implementacija Hlađenja KompriMiranim Hladnim Zrakom Korištenjem Vrtložne Cijevi U Postupku Glodanja]. Ph.D. Thesis, University of Split, Split, Croatia, 25 July 2014.

48. Bandaru, S.; Becerra, V.; Khanna, S.; Espargilliere, H.; Sevilla, L.T.; Radulovic, J.; Hutchinson, D.; Khusainov, R. A General Framework for Multi-Criteria Based Feasibility Studies for Solar Energy Projects: Application to a Real-World Solar Farm. Energies 2021, 14, 2204. [CrossRef]

49. Jamwal, A.; Agrawal, R.; Sharma, M.; Kumar, V. Review on multi-criteria decision analysis in sustainable manufacturing decision making. Int. J. Sustain. Eng. 2021, 14, 202-225. [CrossRef]

50. Watson, H.J. Revisiting Ralph Sprague's Framework for Developing Decision Support Systems. Commun. Assoc. Inf. Syst. 2018, 42, 363-385. [CrossRef]

51. Temuçin, T.; Tozan, H.; Valícek, J.; Harnicarova, M. A Fuzzy based decision support model for Non-traditional machining process selection. Tech. Gaz. 2013, 20, 787-793.

52. Taha, Z.; Rostam, S. A hybrid fuzzy AHP-PROMETHEE decision support system for machine tool selection in flexible manufacturing cell. J. Intell. Manuf. 2012, 23, 2137-2149. [CrossRef]

53. Alberti, M.; Ciurana, J.; Rodríguez, C.A.; Özel, T. Design of a decision support system for machine tool selection based on machine characteristics and performance tests. J. Intell. Manuf. 2011, 22, 263-277. [CrossRef]

54. Balazinski, M.; Bellerose, M.; Czogala, E. Application of fuzzy logic techniques to the selection of cutting parameters in machining processes. Fuzzy Sets Syst. 1994, 63, 307-317. [CrossRef]

55. Niamat, M.; Sarfraz, S.; Ahmad, W.; Shehab, E.; Salonitis, K. Parametric Modelling and Multi-Objective Optimization of Electro Discharge Machining Process Parameters for Sustainable Production. Energies 2020, 13, 38. [CrossRef]

56. Ming, W.; Shen, F.; Zhang, G.; Liu, G.; Du, J.; Chen, Z. Green machining: A framework for optimization of cutting parameters to minimize energy consumption and exhaust emissions during electrical discharge machining of Al 6061 and SKD 11. J. Clean. Prod. 2021, 285, 124889. [CrossRef]

57. Wittbrodt, P.; Paszek, A. Decision support system of machining process based on the elements of fuzzy logic. Int. J. Mod. Manuf. Technol. 2015, 7, 81-85.

58. Vidal, A.; Alberti, M.; Ciurana, J.; Casadesús, M. A decision support system for optimising the selection of parameters when planning milling operations. Int. J. Mach. Tools Manuf. 2005, 45, 201-210. [CrossRef]

59. Plaza, M.; Zebala, W.; Matras, A. Decision system supporting optimization of machining strategy. Comput. Ind. Eng. 2019, 127, 21-38. [CrossRef]

60. Shin, S.-J.; Kim, D.B.; Shao, G.; Brodsky, A.; Lechevalier, D. Developing a decision support system for improving sustainability performance of manufacturing processes. J. Intell. Manuf. 2015, 28, 1421-1440. [CrossRef]

61. Khan, A.M.; Jamil, M.; Salonitis, K.; Sarfraz, S.; Zhao, W.; He, N.; Mia, M.; Zhao, G. Multi-Objective Optimization of Energy Consumption and Surface Quality in Nanofluid SQCL Assisted Face Milling. Energies 2019, 12, 710. [CrossRef]

62. Ransikarbum, K.; Pitakaso, R.; Kim, N.; Ma, J. Multicriteria decision analysis framework for part orientation analysis in additive manufacturing. J. Comput. Des. Eng. 2021, 8, 1141-1157. [CrossRef]

63. Ransikarbum, K.; Khamhong, P. Integrated Fuzzy Analytic Hierarchy Process and Technique for Order of Preference by Similarity to Ideal Solution for Additive Manufacturing Printer Selection. J. Mater. Eng. Perform. 2021, 9, 1-12. [CrossRef]

64. Boumaiza, A.; Sanfilippo, A.; Mohandes, N. Modeling multi-criteria decision analysis in residential PV adoption. Energy Strat. Rev. 2021, 39, 100789. [CrossRef]

65. Chanthakhot, W.; Ransikarbum, K. Integrated IEW-TOPSIS and Fire Dynamics Simulation for Agent-Based Evacuation Modeling in Industrial Safety. Safety 2021, 7, 47. [CrossRef]

66. Mladineo, M.; Veža, I. Ranking enterprises in terms of competences inside regional production network. Croat. Oper. Res. Rev. 2013, 4, 65-75.

67. Nemery, P. On the Use of Multicriteria Ranking Methods in Sorting Problems. Ph.D. Thesis, Université Libre de Bruxelles, Brussels, Belgium, November 2008.

68. Brans, J.P.; Vincke, P.; Mareschal, B. How to select and how to rank projects: The Promethee method. Eur. J. Oper. Res. 1986, 24, 228-238. [CrossRef]

69. Kumar, R.; Bilga, P.S.; Singh, S. Multi-objective optimization using different methods of assigning weights to energy consumption responses, surface roughness and material removal rate during rough turning operation. J. Clean. Prod. 2017, 164, 45-57. [CrossRef]

70. Jajac, N.; Knezic, S.; Marovic, I. Decision support system to urban infrastructure maintenance management. Organ. Technol. Manag. Constr. 2009, 1, 72-79. 
71. Sidhu, A.S.; Singh, S.; Kumar, R.; Pimenov, D.Y.; Giasin, K. Prioritizing Energy-Intensive Machining Operations and Gauging the Influence of Electric Parameters: An Industrial Case Study. Energies 2021, 14, 4761. [CrossRef]

72. Kumar, R.; Singh, S.; Bilga, P.S.; Jatin, K.; Singh, J.; Singh, S.; Scutaru, M.-L.; Pruncu, C.I. Revealing the benefits of entropy weights method for multi-objective optimization in machining operations: A critical review. J. Mater. Res. Technol. 2021, 10, $1471-1492$. [CrossRef] 